\title{
Artículos
}

\section{Vivienda de interés social, segregación residencial y accesibilidad: análisis de 121 conjuntos urbanos en el arco nororiente del Valle de México, 2001-2010}

\section{Social housing, residential segregation and accessibility: Analysis of 121 urban groups in the northeastern arc of the Valley of Mexico, 2001-2010}

\author{
Jorge Alberto Montejano Escamilla* \\ Camilo Alberto Caudillo Cos** \\ Mauricio Cervantes Salas***
}

\section{Resumen}

Este estudio indaga el grado de segregación residencial en los municipios que han albergado la construcción de 121 conjuntos de vivienda social, edificados en el arco nororiente del Valle de México durante el decenio 2000-2010, así como las variaciones en el grado de accesibilidad de los propios conjuntos urbanos en el mismo periodo. Mediante indicadores de accesibilidad, de autocorrelación espacial, y la contabilización de la oferta y demanda de vivienda social, se concluye que existe un alto grado de segregación en estos conjuntos residenciales y los municipios que los albergan con respecto a los municipios centrales del Valle de México; que esta segregación tiende a reducirse mínimamente con el paso del tiempo para algunas de

* Centro de Investigación en Geografía y Geomática "Ing. Jorge L. Tamayo", A.C. (CentroGeo). Dirección postal: Contoy 137, Lomas de Padierna, Tlalpan, 14240, Ciudad de México, México. Correo electrónico: jmontejano@centrogeo.edu.mx

** Centro de Investigación en Geografía y Geomática "Ing. Jorge L. Tamayo", A.C. (CentroGeo). Dirección postal: Contoy 137, Lomas de Padierna, Tlalpan, 14240, Ciudad de México, México. Correo electrónico: ccaudillo@centrogeo.org.mx

*** Centro de Investigación en Geografía y Geomática "Ing. Jorge L. Tamayo", A.C. (CentroGeo). Dirección postal: Contoy 137, Lomas de Padierna, Tlalpan, 14240, Ciudad de México, México. Correo electrónico: mcervantes@centrogeo.org.mx

Nota de los autores: Investigación apoyada por el Fondo de Proyectos de Desarrollo Científico para Atender Problemas Nacionales 2014, CONACYT PDCPN2014-248127.

D.R. (C) 2018. Estudios Demográficos y Urbanos Licencia Creative Commons Atribución-NoComercial-SinDerivar (CC BY-NC-ND) 4.0 Internacional 
las variables estudiadas; y que la sobreoferta de vivienda social puede haber favorecido la segregación residencial en escala metropolitana.

Palabras clave: vivienda social; segregación residencial; política pública; Valle de México.

\begin{abstract}
This study investigates the degree of residential segregation in the municipalities that have hosted the construction of 121 social housing complexes, built in the northeastern corner of the Valley of Mexico during the 2000-2010 decade, as well as variations in the degree of accessibility of these urban complexes during the same period. Through indicators of accessibility, spatial autocorrelation, and measurements of the supply and demand of social housing, the authors conclude that there is a high degree of segregation in these residential complexes and the municipalities that house them with respect to the central municipalities of the Valley of Mexico. This segregation is slightly reduced over time for some of the variables studied, while the oversupply of social housing may have contributed to residential segregation on a metropolitan scale.
\end{abstract}

Keywords: social housing; residential segregation; public policies; Valley of Mexico.

\title{
Introducción
}

En América Latina, los esquemas de extensión y fragmentación de la inversión para la producción inmobiliaria han reforzado y ampliado los procesos de segregación espacial (Rufino, 2015: 88). Monkkonen (2012a: 142) señala que en México, los nuevos proyectos habitacionales crean una nueva forma de urbanización, con más infraestructura que la que es irregular, pero más homogéneos y densos. La nueva política de vivienda y la expansión del financiamiento de vivienda han generado cambios en los niveles de segregación en el sistema urbano mexicano desde 1990, aumentando la segregación socioeconómica en las ciudades con más construcción de nuevos conjuntos habitacionales.

Durante el primer decenio del siglo veintiuno, la política de desarrollo de vivienda social en México promovió la construcción masiva de nuevos conjuntos habitacionales en municipios de las periferias urbanas y favoreció una baja mezcla de uso de suelo. En tal contexto, cabe preguntarse si estos nuevos conjuntos han incrementado la segregación residencial; cuáles han sido los efectos sobre el grado de accesibilidad de dicha población a satisfactores básicos -entendido el grado de accesibilidad como un efecto directo (positivo o negativo) de la segregación-; y si este "proceso", como de- 
nomina Sabatini a la segregación residencial (Sabatini 2006: 9), ha evolucionado con el tiempo. Tales cuestionamientos se enmarcan en la necesidad de estudiar con más detalle "la importancia que tienen la localización y el grado de segregación de la vivienda social en la profundización de [...] las diferencias sociales" (Sabatini y Wormald, 2013: 17). Sobre ello, Eibenschutz y Goya $(2010,27)$ apuntan que la producción masiva de vivienda de interés social implementada en México, ha propiciado la construcción de conjuntos habitacionales distantes y limítrofes al área urbana, que al no formar parte integral de la estructura vial, rompen con la continuidad espacial de las ciudades y dificultan la accesibilidad a otros satisfactores, como son los centros de empleo, equipamiento educativo, salud, cultura y recreación, factores que en última instancia favorecen la desocupación de la vivienda.

Este artículo centra su análisis en los municipios metropolitanos que han albergado la edificación de 121 nuevos conjuntos habitacionales de interés social entre 2000 y 2010 , así como en los propios conjuntos, ubicados principalmente en el arco nororiente de la Zona Metropolitana del Valle de México (ZMVM). En el primer apartado se exponen sucintamente las bases teóricas del concepto de segregación residencial y sus efectos, con énfasis en la accesibilidad. Para comprender los factores estructurantes de la segregación, en los dos siguientes apartados se hace una breve semblanza de la evolución de la política de vivienda de interés social y sus inconsistencias, y posteriormente se describen la forma de crecimiento y la estructura urbana adoptadas por la ZMVM. En la cuarta sección se especifica la metodología empleada para la construcción de los indicadores de accesibilidad como efecto directo del proceso de segregación residencial. Los resultados del presente estudio son analizados en el quinto apartado, dejando para el último acápite algunas conclusiones.

\section{Segregación residencial y accesibilidad}

El origen conceptual de la segregación puede adjudicarse a la escuela sociológica de Chicago; "Robert E. Park afirmaba que el interés de las ciencias sociales en el estudio de la distribución espacial de la población radicaba en que las distancias físicas podrían considerarse indicadores de distancias o diferencias sociales" (Rodríguez, 2014).

Massey y Denton (1988: 282) plantean que "la segregación residencial es el grado en que dos o más grupos viven separados uno del otro, en diferentes partes del entorno urbano". De acuerdo con Rodríguez y Arriagada 
(2004) y Castells (1976), la segregación residencial remite a la desigual distribución de grupos de población en el territorio, la cual puede manifestarse de múltiples maneras, como la proximidad física entre los espacios residenciales de diferentes grupos sociales, la homogeneidad social de los grupos sociales contenidos en subdivisiones territoriales, o la concentración de grupos sociales en zonas específicas de una ciudad. Para Sabatini,

la segregación social del espacio urbano, conocida también como segregación residencial, es un fenómeno espacial con complejas conexiones a diferencias e inequidades sociales $[\ldots]$ la segregación residencial corresponde a la aglomeración espacial de familias de similar condición social [Sabatini, 2006: 7].

El autor argumenta que la segregación residencial es un concepto multidimensional, donde se combinan el grado de concentración espacial de los grupos sociales, la homogeneidad social que presentan diferentes áreas centrales de las ciudades, y el prestigio o falta de éste de los diferentes barrios de cada ciudad (Sabatini, 2006: 7). Las primeras dos corresponden a dimensiones objetivas y generalmente son cuantificadas mediante un coeficiente de disimilaridad, mientras que la tercera es de naturaleza subjetiva y se refiere a la imagen colectiva de una determinada zona homogénea. Massey y Denton (1988) argumentan que debido a esta característica multidimensional, la segregación residencial no puede ser medida con un solo índice, por lo que proponen una batería de indicadores (i.e. índices de disimilaridad, Gini, Atkinson, Delta, etc.) para poder comprender a profundidad las distintas dimensiones como la igualdad en la distribución de los grupos sociales, su grado de concentración espacial, o el nivel de exposición de un grupo determinado. A este respecto, Garrocho y Campos (2013) cuestionan estos tradicionales índices, argumentando problemas en los resultados derivados de la a-espacialidad de los mismos, proponiendo entonces la utilización de indicadores "genuinamente espaciales" como los de autocorrelación espacial (global y local de Moran), utilizados ampliamente en estudios territoriales y en el presente estudio.

Rodríguez y Arriagada (2004) señalan que en el análisis de la segregación destaca la importancia del componente espacial como mecanismo relacionado con la reproducción de las desigualdades socioeconómicas entre los grupos poblacionales. En tal sentido, Wormald et al. (2013) han problematizado la segregación residencial como una geografía de oportunidades partiendo del marco conceptual brindado por Galster y Killen (1995), perspectiva que se interesa por estudiar hasta dónde la condición de segregación se vincula con falta de acceso o acceso limitado a oportunidades de vida. 
Esta perspectiva ha sido abordada en trabajos recientes por Fuentes y Hernández (2013), quienes desarrollan su investigación empírica sobre la relación entre la segregación socioespacial y la accesibilidad a los centros de empleo en Ciudad Juárez, y quienes afirman que existen dos corrientes diferentes sobre segregación residencial: la segregación por diferenciación (Duncan y Duncan, 1975), "definida como la exclusión espacial de algunos grupos sociales con respecto a los recursos urbanos", y la denominada "segregación por localización", caracterizándola como la exclusión social entre grupos sociales (Alegría, 2009).

Sabatini (2006) -inserto en la primera corriente- teoriza sobre los efectos de la segregación residencial, argumentando que éstos pueden ser positivos y negativos (véase también Sabatini, Cáceres y Cerda, 2001). Como positivos podríamos pensar en la preservación de la cultura de un grupo social; como negativos plantea una reducción en la interacción de diferentes clases sociales. En este segundo grupo entraría la reducción en la accesibilidad a los satisfactores básicos (educación, salud, empleo). Distinguiendo claramente que segregación residencial no es sinónimo de pobreza (aun cuando se haya utilizado el término en el ámbito latinoamericano), Sabatini, Cáceres y Cerda (2001) desarrollan el concepto de "malignidad de la segregación residencial" para explicar las consecuencias negativas de la segregación espacial de los pobres y en el que los efectos positivos de la misma segregación han tendido a desaparecer en la mayoría de las ciudades latinoamericanas. Como efecto de esta malignidad destacan la ilegalidad, irregularidad e informalidad de los asentamientos periféricos de las ciudades latinoamericanas, expresado ello por la "falta de servicios urbanos y las malas condiciones de accesibilidad" (Sabatini, Cáceres y Cerda, 2001:37).

Kain (1968) postuló la llamada hipótesis del desajuste espacial, que combinaba los patrones de segregación de la población afroamericana y el cambio en la distribución espacial de los empleos. Según Kain, otro de los mecanismos de perpetuación de la segregación es la operación de los mercados de vivienda: con ocupaciones de salarios bajos la población no puede cambiar su residencia. Es aquí donde entra el factor de la accesibilidad al empleo como una forma maligna de interacción con la segregación: el patrón de localización del empleo en las ciudades norteamericanas tendió a la suburbanización (precios bajos en las periferias atrajeron a las empresas, que fueron abandonando poco a poco el centro de las ciudades). La vivienda suburbana, por otro lado, comenzó a ser sólo asequible para los sectores de altos ingresos, lo que dejó a la población afroamericana enfrentando altos costos de traslado hacia los empleos, en el mejor de los casos, y en el peor en el desempleo, representando esta situación -a grandes rasgos-el desajuste 
entre vivienda y empleo. En el caso de la ZMVM, tenemos una tendencia de segregación de los sectores populares opuesta. Su localización tiende a ser periférica, en urbanizaciones informales (Garcés-Fierros, 2009: 88; Lazcano, 2005: 38), y más recientemente en desarrollos de vivienda social altamente homogéneos con un grado alto de aislamiento de servicios básicos. La estructura de la economía de la ciudad está altamente centralizada (30\% de todos los empleos se localizan en tres delegaciones) (Caudillo y Flores, 2016: 133), por lo que la población de bajos ingresos, con empleos precarios y con grado bajo de escolaridad (rasgos distintivos de los sectores populares segregados en la periferia) enfrentarán mayores dificultades para acceder al empleo formal ubicado en las zonas centrales de la ciudad.

\section{Evolución de las políticas de vivienda social en México 1910-2010}

Es posible identificar al menos cinco periodos distintos en la evolución de las políticas de vivienda social en México. El primero (1917-1940) se caracterizó por la institucionalización del financiamiento de vivienda social para los trabajadores. Ello quedó plasmado en el artículo 123 de la Constitución Política de los Estados Unidos Mexicanos de 1917. Para cumplimentarlo, se obligó a los patrones a aportar parte de los ingresos de los trabajadores a un fondo nacional de crédito, lo que dio pie a la aparición de las primeras bancas de desarrollo, instituciones que se encargarían de atender el problema del financiamiento de vivienda otorgando créditos principalmente a burócratas estatales (Perló, 1979: 784).

El periodo 1940-1970 se caracterizó por robustecer el aparato estatal encargado del financiamiento de vivienda para los trabajadores al servicio del Estado mexicano y ampliar la dotación de acceso a la vivienda de los sectores económicamente más desfavorecidos. Para ello se crearon el Instituto Mexicano del Seguro Social (IMSS), el Instituto Nacional de la Vivienda (INV) o el Fondo de Operación y Financiamiento Bancario a la Vivienda (Fovi). A pesar de que las acciones de financiamiento y producción de vivienda en el país fueron limitadas (García, 2010), durante esta etapa se consolidó el carácter regulador del Estado en materia de política de vivienda para así responder a las crecientes demandas de un México cada vez más industrializado y urbano.

El periodo 1970-1988 se definió por fortalecer el marco jurídico e institucional, del que desembocaron una gestión y una planeación urbanas institucionalmente desarticuladas: la promulgación de la Ley de Asentamien- 
tos Humanos (1976) consolidó la planeación urbana regional (Rébora, 1978: 1181), mientras que las reformas al artículo 115 constitucional dotaron de mayor autonomía a los gobiernos municipales para atender las demandas de vivienda, dislocando la planeación regional de la local y derivando en un crecimiento anárquico de las ciudades. En este contexto, en 1972 se creó el Instituto del Fondo Nacional de la Vivienda para los Trabajadores (Infonavit), constituyéndose como la instancia con mayor capacidad para financiar y producir vivienda: tan sólo entre 1972 y 1981 construyó casi 38\% del total nacional para ese periodo (García y Puebla, 1998). Aun con ello, hacia 1986 la producción de vivienda social solamente cubría $17 \%$ de la demanda. Para satisfacer las necesidades de la población de menores ingresos, se creó en 1981 el Fondo de Habitaciones Populares (Fonhapo), institución que nació para financiar viviendas y conjuntos habitacionales populares pero que terminaría subsidiando enteramente la vivienda de autoconstrucción, de forma que ninguna de estas instituciones pudo resolver el problema del acceso a créditos a vivienda para los sectores poblacionales más desfavorecidos (Aldrete-Haas, 1991; Maya et al., 2008: 8).

Durante el periodo 1988-2000 los esquemas de financiamiento fueron modificados sustancialmente; siguiendo las recomendaciones de diversos organismos internacionales, el Estado mexicano redujo su papel en la producción y financiamiento de vivienda social mediante la desregulación financiera, la cual permitiría la participación de la banca privada en el otorgamiento de préstamos hipotecarios para el financiamiento de la construcción de vivienda social (García, 2010; Maya et al., 2008; Monkkonen, 2011). Ello se hizo patente hacia 1992, cuando se creó el Programa para el Fomento y Desregulación de la Vivienda, el cual "establecía como objetivo central la disminución del papel regulador del Estado mexicano en la actividad para el desarrollo de la vivienda" (Boils, 2004: 350-351). Entre otras, las medidas impuestas comprendieron "la supresión de subsidios, la restricción del otorgamiento de crédito para la adquisición de terrenos, la simplificación de los procedimientos burocráticos" (Mellado, 2013: 27), y "transferir a los gobiernos municipales — desde los gobiernos estatales y el federal - una mayor participación de las acciones habitacionales" (Boils, 2004: 351). El resultado fue una gestión urbana abiertamente empresarial, que reforzó la autonomía municipal para catapultar el desarrollo del sector inmobiliario y nuevamente relegó a los sectores sociales menos favorecidos, lo cual quedó claramente expresado en la distribución porcentual de recursos por tipo de vivienda construida en 1993: 37\% a producción de vivienda residencial, $35 \%$ para clase media, y $28 \%$ para interés social (García y Puebla, 1998). 
En suma, el abandono del Estado como promotor y gestor de la vivienda, aunado a la transformación del régimen jurídico de la tierra, ${ }^{1}$ permitió la construcción de "miles de casitas" en la periferia de las ciudades, a mano de desarrolladores privados (García, 2010: 43), que favorecieron la segregación residencial. Ello ha sido verificado por Monkkonen (2012), quien sugiere que el crecimiento en la segregación socioeconómica a escala de barrio durante la segunda parte de los años noventa del siglo pasado, está fuertemente asociada con la proporción de nueva vivienda social adquirida bajo el nuevo sistema financiero, principalmente debido a la homogeneización de la población de bajos ingresos, y a lo cual se le suma que estos conjuntos carecieron de una adecuada dotación de infraestructura y servicios urbanos (Maya et al., 2008). El periodo más reciente (2000-2012) se basó en el desarrollo masivo de vivienda social que "privilegió los criterios financieros y destacó la función del mercado como instancia rectora del sector" (Mellado, 2013: 28), para lo cual puso en marcha un ambicioso Programa Nacional de Vivienda (2001-2006). Los resultados son contundentes: mientras que en los ochenta se otorgaron anualmente cerca de 150000 hipotecas, en 1990 alcanzaron 220000 hipotecas, y entre 2000-2005 rebasaron las 400000 (Monkkonen, 2012: 758). En 2004, el financiamiento de vivienda se otorgaba principalmente al sector privado formal y a sectores de población con salarios modestos (CIDOC, 2004), ${ }^{2}$ y entre 2001 a 2005 se otorgaron 3.4 millones de créditos para adquisición y mejoramiento de vivienda (CIDOC, 2006). En 2005 las instituciones financieras privadas (bancos y sociedades financieras de objeto limitado) concedieron $25 \%$ del total de créditos de las viviendas financiadas (CIDOC, 2006), y hacia 2008 México se convertía en el mercado de bonos respaldados por hipotecas residenciales más grande en Latinoamérica (CIDOC, 2007). Esta vorágine edilicia no tardó en cobrar factura: en el reporte de la CIDOC de 2012 se reconoce que el explosivo crecimiento de las manchas urbanas en México se explica en parte por la producción institucionalizada de nueva vivienda en las periferias urbanas, condición identificada por Sabatini (2006) en ciudades latinoamericanas como un elemento precursor de los efectos negativos en la segregación residencial. El documento explica que por ello se experimentó un aumento en

${ }^{1}$ Las reformas al artículo 27 constitucional de 1992 buscaban que los desarrolladores pudieran incorporar tierras ejidales y comunales para el crecimiento urbano ordenado, crear reserva de suelo urbano necesario para la construcción de viviendas, y con ello reducir la venta ilegal de la propiedad social (Olivera, 2005; Catalán, 1993).

$2 \mathrm{Al}$ delegar al mercado el financiamiento de la vivienda, nuevamente amplios sectores de población con muy bajos ingresos tuvieron que recurrir a la autoconstrucción (el Centro de Investigación y Documentación de la Casa, A.C. -CIDOC- consigna que en 2004 la mitad de las nuevas edificaciones provenían de este proceso).

Estudios Demográficos y Urbanos, vol. 33, núm. 1 (97), 2018, pp. 187-224

ISSN 0186-7210; e-ISSN 2448-6515; doi: http://dx.doi.org/10.24201/edu.v33i1.1639 
la desocupación de vivienda (que hacia 2011 había alcanzado cifras cercanas a 21\% del parque habitacional nacional ofertado) ${ }^{3}$ (CIDOC, 2011: 28), al tiempo que subraya la falta de coordinación entre los distintos niveles de gobierno (federal, estatal y municipal) y la escasa capacidad técnica de los municipios para hacer frente a procesos de planeación.

\section{Estructura de la Zona Metropolitana del Valle de México (ZMVM)}

La ZMVM tiene una superficie aproximada de $7854 \mathrm{~km}^{2}$ y una población cercana a los 20.1 millones de habitantes. Abarca 16 delegaciones políticas ${ }^{4}$ de la Ciudad de México (CDMX), 59 municipios del Estado de México y un municipio del Estado de Hidalgo. El crecimiento urbano reciente de la ZMVM es de tipo discontinuo, caracterizado por la aparición de enclaves urbanos dispersos y aislados de la trama urbana, resultantes de un proceso identificado como "atomización periférica", el cual se refiere a un proceso de ocupación del territorio puntual, fragmentado, de baja densidad y generalmente con ausencia de servicios. La ZMVM tiene una estructura urbana fuertemente fragmentada y segregada residencialmente, fenómenos que se expresan abiertamente en el territorio (Figura 1). Por una parte, los grupos de menor ingreso se encuentran principalmente asentados en la inadecuada y otrora zona lacustre del oriente y en algunas de las laderas de las montañas, mientras que en la zona poniente y sur (con mayor riqueza en ecosistemas naturales) se asientan los grupos de más ingresos. A esta estructura principal le sobreviene una envolvente caracterizada por albergar la mayor parte del nuevo crecimiento metropolitano y por la implantación de enormes conjuntos de vivienda de interés social ubicados en los municipios colindantes con la Ciudad de México.

Esta estructura es primordialmente resultado de una histórica concentración geográfica de los poderes administrativos, de un débil marco regulatorio en materia de ordenación territorial, y de la masiva ocupación irregular del suelo. La expansión física de la metrópoli, allende sus límites políticoadministrativos, puede ser resumida por los siguientes factores: un enorme crecimiento económico ${ }^{5}$ acontecido a mediados del siglo XX que indujo un

${ }^{3}$ De acuerdo con Monkkonen, la tasa de desocupación según el Censo 2010 era de $14 \%$. Aun con ello, estaría cuatro puntos por encima del promedio internacional (Monkkonen, 2014: 3).

${ }^{4}$ Delimitación político-administrativa similar a un municipio.

${ }_{5}^{5}$ Crecimiento económico dado principalmente por un fuerte impulso al desarrollo industrial y a una política económica basada en la sustitución de importaciones. 


\section{Figura 1}

Esquema general de la estructura territorial de la ZMVM
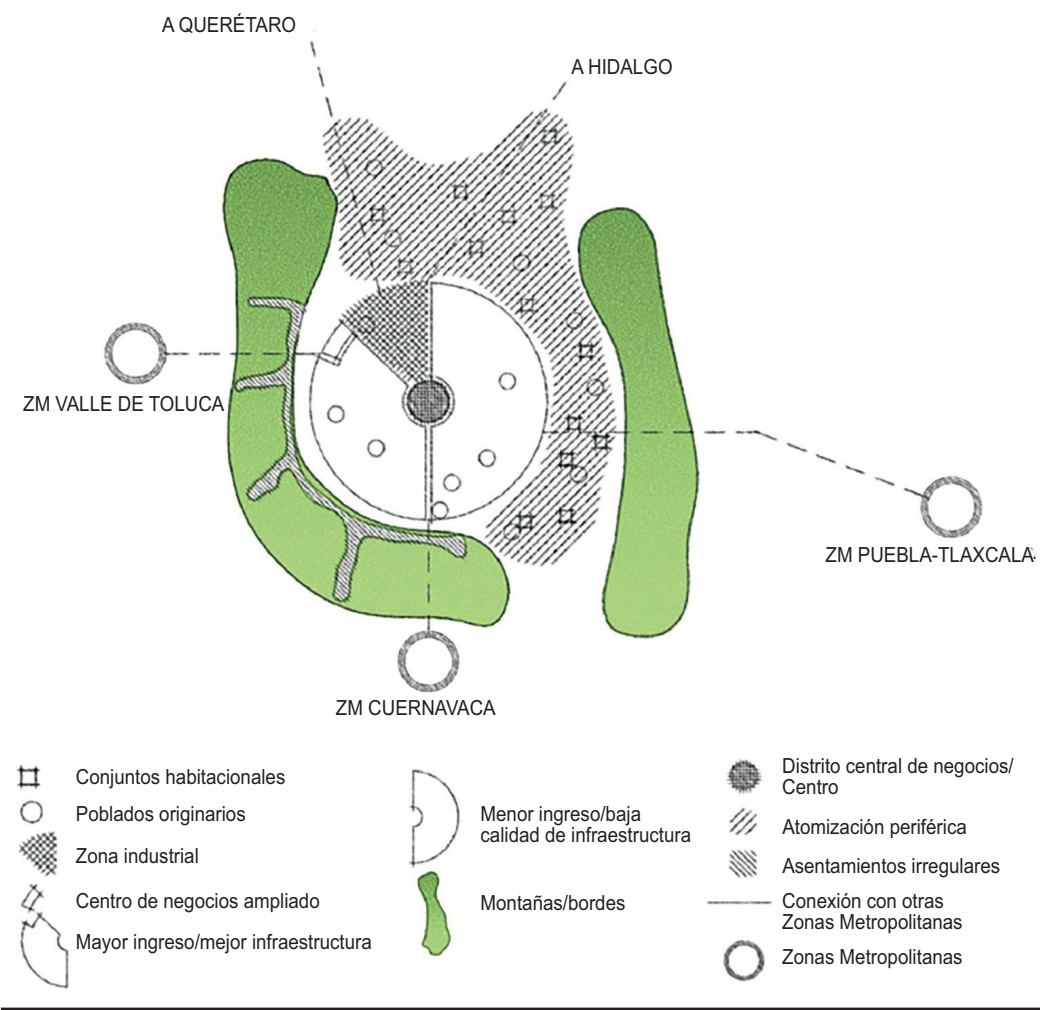

Fuente: Elaboración propia.

significativo aumento demográfico, principalmente debido a la masiva movilización campo-ciudad; una posterior expulsión de la población de menores ingresos de la Ciudad de México a las nuevas periferias industriales localizadas en los límites con el Estado de México; 6 y una fase de consolidación del proceso de metropolización alcanzado en la década de los ochenta, en la cual el crecimiento demográfico se concentró en los municipios periféricos (Rébora, 2000; Lindón, 1997). Este crecimiento de tipo centrífugo ha sido atribuido a una transformación en la base económica (desindustrialización)

${ }^{6}$ Principalmente por la restricción impuesta para el asentamiento fabril y de vivienda social dentro de la Ciudad de México hacia los años cincuenta. 
y a una especialización territorial que resultó en una alta fragmentación del tejido urbano. Hasta los años noventa, estos fenómenos promovieron la elevación de las rentas en áreas centrales, el despoblamiento de las mismas, y consecuentemente la ocupación indiscriminada de áreas periféricas con mayor valor natural (Pradilla, 2000). Parte de este crecimiento desordenado tiene sus bases en la apropiación ilegal y el uso irregular del suelo, producto de la histórica marginación de los estratos sociales más bajos del mercado formal del suelo y la vivienda (Metrópoli 2025, 2006).

\section{Metodología}

Para definir el ámbito de estudio, se seleccionaron el total de conjuntos urbanos reportados como autorizados entre 2000 y 2010, dentro de la base de datos generada por la Secretaría de Desarrollo Urbano y Metropolitano del Estado de México correspondientes a los municipios de la ZMVM con una TMCA por encima de 3\%. La muestra final fue de 121 conjuntos urbanos que pudieron ser adecuadamente geolocalizados. ${ }^{7}$ En este trabajo se adopta la noción de segregación por diferenciación, y se aplican indicadores de accesibilidad para captar la "malignidad" a la que refieren Sabatini, Cáceres y Cerda (2001) para dos cortes temporales (2005 y 2010), con el objetivo de observar la evolución en el tiempo. Adicionalmente se aplicaron indicadores de autocorrelación espacial por cada indicador, como lo proponen Garrocho y Campos (2013) para verificar el grado de homogeneidad / heterogeneidad, y observar con ello los patrones de la segregación residencial. Al registrarse altas concentraciones espaciales se estaría verificando segregación residencial por homogeneidad de dichas características. A continuación se describe cada uno de los indicadores desarrollados.

1. Accesibilidad laboral como efecto de la segregación. Para el total de los municipios de la ZMVM se calculó un índice de accesibilidad al empleo para ocho sectores de actividad económica en el nivel de área geoestadística básica (AGEB), y un índice de accesibilidad total. Es importante señalar que los sectores de actividad económica analizados aglutinan $86 \%$ de los empleos formales en la ZMVM. La accesibilidad al empleo se calculó mediante la siguiente fórmula (Haas et al., 2010):

7 Véanse los municipios metropolitanos de estudio en el Cuadro 1.

Estudios Demográficos y Urbanos, vol. 33, núm. 1 (97), 2018, pp. 187-224

ISSN 0186-7210; e-ISSN 2448-6515; doi: http://dx.doi.org/10.24201/edu.v33i1.1639 


$$
E=\sum_{i=1}^{n} \frac{p_{i}}{r_{i}^{2}}
$$

donde $E$ es el índice de accesibilidad al empleo para una AGEB dada; $n$ es el número total de AGEB en la región de estudio; $p_{i}$ es el número de empleos en el í-esimo AGEB; y $r_{i}$ es la distancia Manhattan (en kilómetros) del centroide de un AGEB dado al centroide del í-ésimo AGEB. El índice ayuda a entender la accesibilidad al empleo de mejor manera que la densidad del empleo, ya que toma en cuenta todos los empleos de la región (Haas et al. 2010, 36).

2. Accesibilidad a educación y salud a nivel de AGEB para la ZMVM. Como complemento al estudio de la segregación, se estimó el grado de accesibilidad a equipamientos educativos públicos y se analizó el porcentaje de población sin derecho a servicio médico público como proxy de accesibilidad al sistema de salud. Para el caso de la educación, ${ }^{8}$ el Sistema Normativo de Equipamiento Urbano de México (Sedesol, 2012) establece las distancias máximas a las que deben encontrarse las escuelas respecto de la población. Dado que la accesibilidad a la educación no es condición suficiente para la asistencia, se calculó la accesibilidad respecto a los dos niveles de la educación básica (primaria y secundaria) en el nivel de AGEB, con base en datos del Censo de Población y Vivienda 2010 (INEGI, 2010), y se evaluó qué conjuntos habitacionales quedaron fuera del alcance máximo establecido por la regulación. Adicionalmente, se mapeó el comportamiento espacial del rezago educativo. Del mismo modo, se analizó el porcentaje de población sin derecho al servicio de salud pública. Para ambas dimensiones se desarrollaron pruebas de correlación espacial (Índice de Moran Global e Índices Locales de Autocorrelación Espacial, LISA, por sus siglas en inglés).

3. Cálculo del índice de hacinamiento. Se calculó el índice de hacinamiento, que de acuerdo al Instituto Nacional de Estadística y Geografía de México (INEGI) se define como las viviendas en las que hay más de 2.5 ocupantes por habitación. El hacinamiento nos permite conocer las características físicas de la vivienda y si éstas se ajustan a las necesidades de espacio que demandan las familias para desarrollar su vida cotidiana. Se espera

${ }^{8}$ Para el cálculo del índice de accesibilidad educativo y mapas derivados, se integró una base de datos con 11922 centros educativos. Tal y como lo señala Garrocho (2012: 122-124), en la escala metropolitana, el calcular la accesibilidad a través de una red de calles y caminos con impedancias, o hacerlo mediante una distancia Manhattan o euclidiana, no muestra grandes diferencias en los resultados finales, por lo que se optó por el cálculo con base en distancias Manhattan. 
que la ampliación de las viviendas reduzca los niveles de hacinamiento. Dicho indicador se calculó con base en el Censo de Población y Vivienda 2010. En este sentido, Rodríguez y Arraigada (2004) enfatizan la importancia del hacinamiento porque actúa como un mecanismo de reproducción de desigualdades socioeconómicas.

4. Comparación entre demanda y oferta de vivienda social. Para verificar la congruencia de las políticas de vivienda entre los niveles federal y municipal, se recabaron las proyecciones sobre demanda de vivienda futura 2001-2010 de la Conavi y la información sobre necesidades de vivienda futura estipuladas para ese mismo periodo de tiempo en los Planes de Desarrollo Urbano Municipales (PDUM). Los datos obtenidos se contrastaron con la vivienda edificada publicada por las instancias de vivienda para el 2010. Se justifica este cálculo dado que Monkkonen (2012) sostiene que el aumento de la segregación residencial está relacionado en parte con las nuevas políticas de financiamiento de vivienda social en las periferias de las ciudades mexicanas por causa de la homogeneización de rentas bajas en dichas periferias.

\section{Análisis de resultados}

\section{Accesibilidad laboral}

En términos de segregación espacial, resaltamos de este análisis la existencia de una estructura claramente diferenciada con relación a la distribución de la accesibilidad al empleo por sector (Figura 2). Por un lado, tanto el comercio al por menor -que representa 33\% de los trabajos de la ZMVM-como la industria manufacturera -la cual aglutina 9.8\% de los empleos totales-, tienden a concentrarse en los bordes metropolitanos (en contraste con los empleos vinculados al sector servicios, que muestran un fuerte patrón de concentración en la zona central de la ciudad). Lo anterior pareciera matizar ligeramente la señalada "desconexión" de los nuevos conjuntos de vivienda social periurbanos en términos de acceso al empleo. Si bien son los empleos peor remunerados, su concentración espacial periférica permitiría deducir cierto acceso desde los nuevos conjuntos de vivienda social.

Empero, al comparar a detalle la posición de los 121 conjuntos habitacionales, se hace evidente la baja accesibilidad de éstos al empleo. Para ello promediamos el valor de accesibilidad del AGEB más cercana por municipio a cada conjunto habitacional. En la Figura 3 se muestran los gráficos de la distribución del índice de accesibilidad en escala metropolitana transformada 


\section{Figura 2}

Índice de accesibilidad al empleo. A) Empleo total, B) Comercio al por menor, C) Industria, D) Servicios profesionales

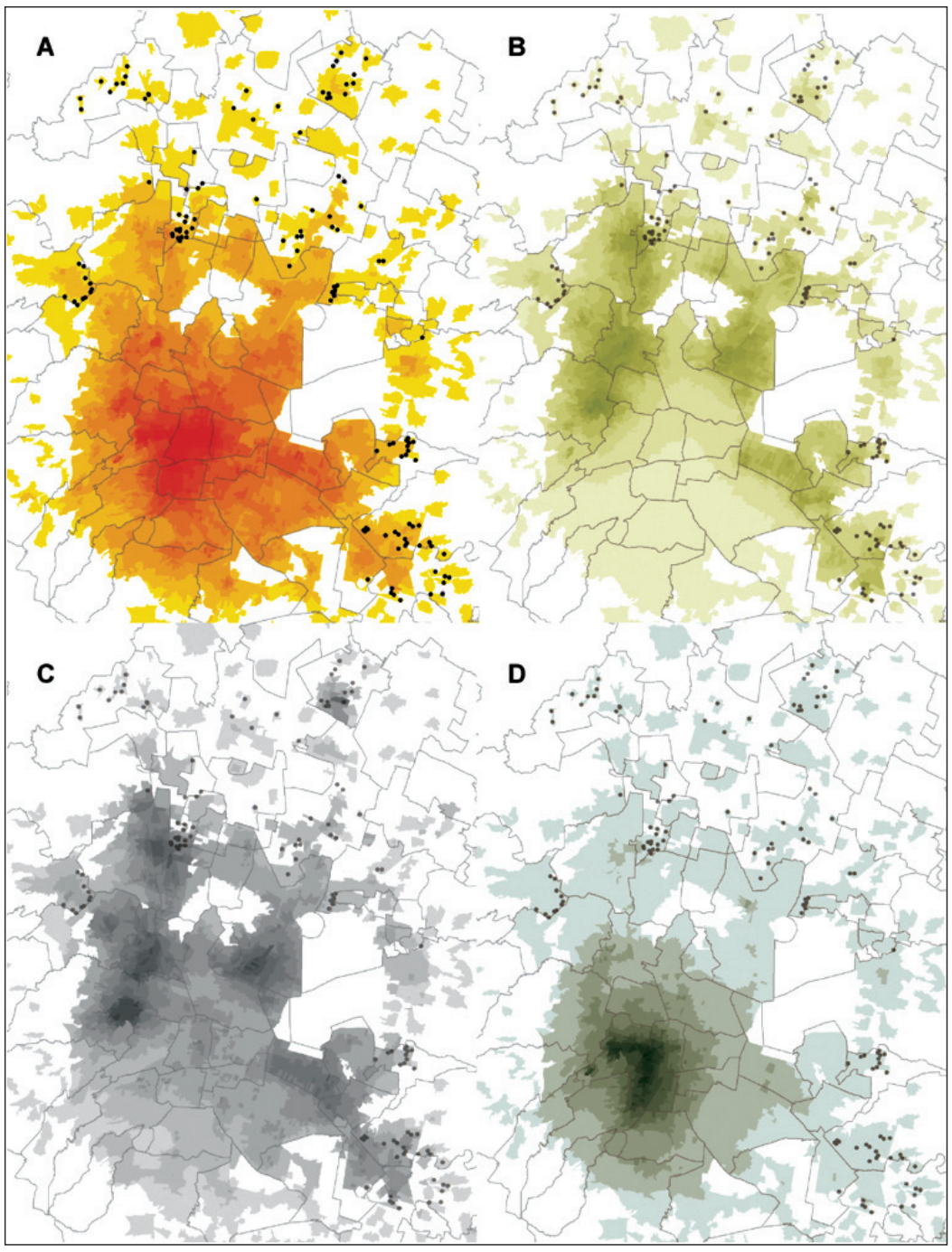

* Los puntos obscuros representan los 121 nuevos conjuntos de vivienda analizados y edificados en el periodo 2000-2010.

Fuente: Elaboración propia con base en INEGI, 2012b.

Estudios Demográficos y Urbanos, vol. 33, núm. 1 (97), 2018, pp. 187-224

ISSN 0186-7210; e-ISSN 2448-6515; doi: http://dx.doi.org/10.24201/edu.v33i1.1639 


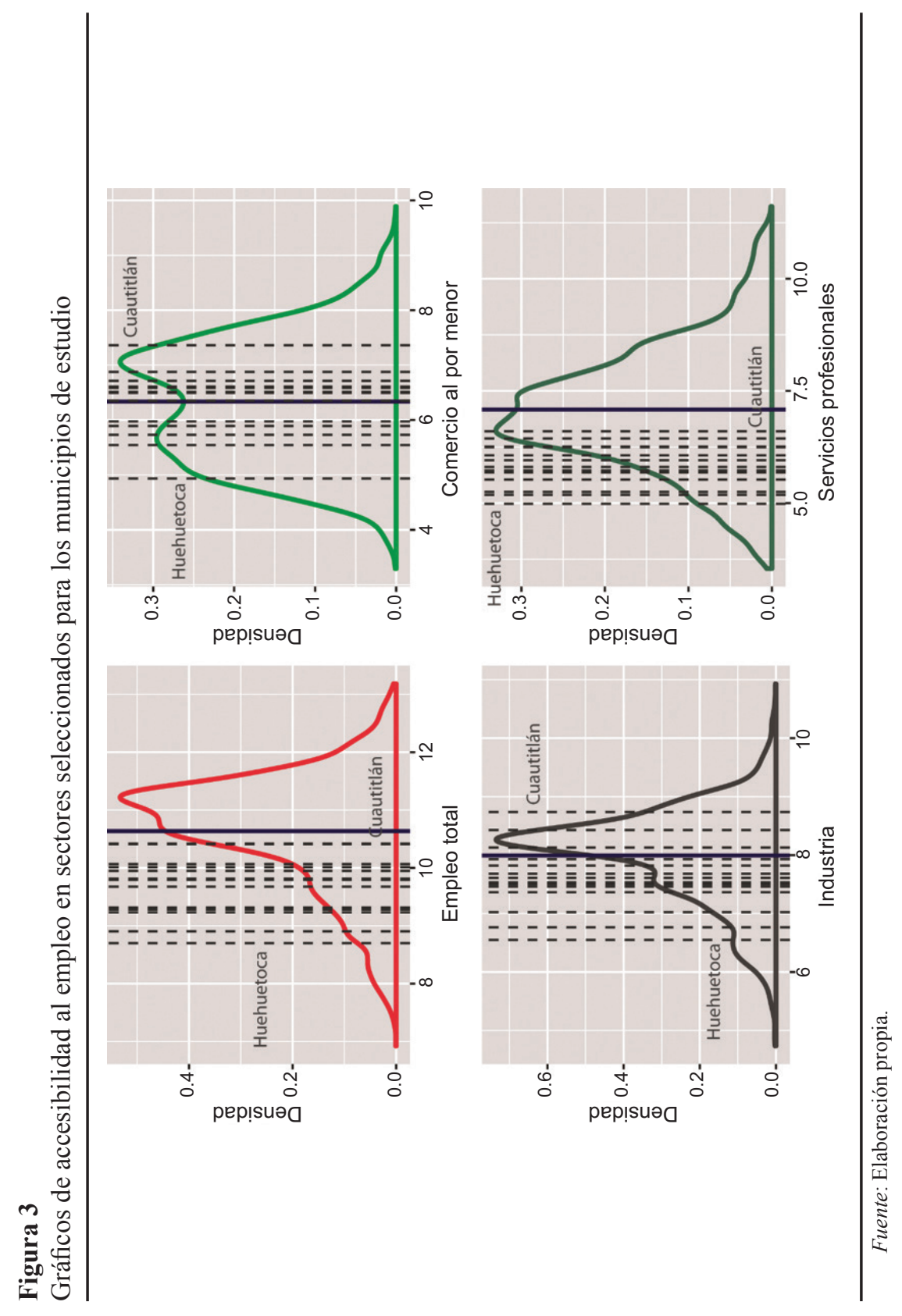


logarítmicamente. Las líneas punteadas corresponden al promedio de los conjuntos por municipio y la línea azul al valor promedio metropolitano. El primer elemento interesante es que los conjuntos asentados en Huehuetoca-uno de los municipios más periféricos de la ZMVM y que registra una de las tasas más altas de vivienda deshabitada- son los que presentan los valores más bajos de accesibilidad. El segundo elemento relevante es que para el empleo total, todos los municipios que albergan los nuevos conjuntos habitacionales se localizan por debajo del valor promedio de accesibilidad metropolitano.

$\mathrm{Al}$ analizar por sectores de actividad, destaca que en acceso al empleo en comercio al por menor, sólo 5 de los 14 municipios de estudio se encuentran por debajo del promedio metropolitano, mientras que en la industria manufacturera, 11 municipios tienen una accesibilidad menor al promedio, siendo una característica común a estos dos sectores el empleo de población con un perfil de capital humano relativamente bajo. Por su parte, se observa que los conjuntos urbanos asentados en los 14 municipios de estudio tienen valores de accesibilidad a empleos en servicios profesionales menores al promedio metropolitano. Los empleos en servicios profesionales exhiben un patrón más concentrado en torno al centro de la ZMVM y suelen requerir niveles altos de capital humano, lo cual podría explicar los bajos valores de accesibilidad al empleo.

\section{Accesibilidad a educación y salud}

Los resultados (Cuadro 1) muestran que bajo los estándares de la Sedesol (2012), prácticamente toda la ZMVM tendría una cobertura razonable en educación. Aun cuando la mayoría de los conjuntos de vivienda social analizados quedan dentro de las zonas de influencia de los tres niveles que conforman la educación básica, se encontró que Tizayuca es el municipio donde más conjuntos quedan fuera del alcance de algún tipo de escuela.

En el caso del porcentaje de niños que no asisten a la secundaria, se observan altos valores en las zonas periféricas de la ciudad. El rezago educativo, medido como porcentaje de la población de 15 años y más con educación básica incompleta, muestra un patrón típico de centro-periferia. Por otro lado, el porcentaje de población sin derecho a servicio médico público exhibe un patrón aún más acentuado a escala metropolitana. Respecto a la accesibilidad a la educación en sus dos niveles básicos, se aprecia que la asistencia a la educación primaria es casi universal. Los índices de Moran globales muestran la intensidad con la que se agrupan los atributos de interés en el espacio: a valores más altos, mayor concentración espacial (Cuadro 2). 


\section{Cuadro 1}

Conjuntos habitacionales sin carencias educativas de nivel básico por municipio

\begin{tabular}{lcc}
\hline Municipio & $\begin{array}{c}\text { Total } \\
\text { de conjuntos }\end{array}$ & $\begin{array}{c}\text { Conjuntos } \\
\text { sin carencias }\end{array}$ \\
\hline Tizayuca & 12 & 2 \\
Acolman & 9 & 8 \\
Cuautitlán & 16 & 12 \\
Chalco & 11 & 10 \\
Chicoloapan & 12 & 9 \\
Huhuetoca & 11 & 6 \\
Ixtapaluca & 17 & 17 \\
Nextlalpan & 1 & 1 \\
Nicolás Romero & 11 & 7 \\
Tecámac & 13 & 9 \\
Teoloyucan & 1 & 0 \\
Tepotzotlán & 1 & 1 \\
Zumpango & 5 & 4 \\
Valle de Chalco Solidaridad & 1 & 1 \\
Total & 121 & 87 \\
\hline
\end{tabular}

Fuente: Elaboración propia.

\section{Cuadro 2}

Índice global de Moran a escala metropolitana

\begin{tabular}{lc}
\hline \multicolumn{1}{c}{ Variable } & I de Moran \\
\hline Porcentaje de niños que no van a la primaria & 0.13 \\
Porcentaje de niños que no van a la secundaria & 0.24 \\
$\begin{array}{l}\text { Porcentaje de población de 15 años y más que no terminaron } \\
\text { la educación básica (rezago educativo) }\end{array}$ & 0.59 \\
Porcentaje de población sin derecho a servicio médico & 0.59 \\
\hline
\end{tabular}

Fuente: Elaboración propia. 
Los mapas LISA (Local Indicators of Spatial Association), también conocidos como conglomerados espaciales, muestran las regiones de autocorrelación espacial positiva y negativa. Ello permite conocer si una variable se distribuye o no aleatoriamente en el espacio. Existe autocorrelación positiva cuando los valores altos o bajos tienden a agrupase en el espacio, y autocorrelación negativa cuando los valores de la variable de interés están rodeados de vecinos con valores disímiles. A escala metropolitana se aprecia cómo las zonas de más alta segregación se localizan en los municipios periféricos (autocorrelación positiva), siendo los conglomerados de rezago educativo y carencia de derecho a servicios de salud pública particularmente amplios (Figuras 4 a 7).

Para estudiar la escala micro, y dado que 8 de los 121 desarrollos de vivienda social analizados son tan recientes que no existen datos censales disponibles, asignamos los valores censales del AGEB más próxima a cada centroide de cada conjunto. Así, todos los conjuntos tienen algún dato en las variables de interés provenientes del Censo 2010 (INEGI, 2010). Los siguientes gráficos muestran la distribución de las variables de interés para los conjuntos clasificados según el periodo en el que fueron construidos (Figura 8).

La no asistencia a primaria muestra un máximo de $4.8 \%$. Los conjuntos del periodo 2001-2005 tienen un promedio de 1.4\%, mientras que los de 2005-2010 presentan un promedio de $2.0 \%$. A pesar de que la diferencia parece muy pequeña $(0.59 \%)$, ello podría indicar un aumento en la asistencia conforme se va asentando la población en estos conjuntos.

Para la no asistencia a la secundaria, el promedio de los conjuntos más antiguos es menor que el de los más recientes (3.4\% vs. 4.4\%). En este caso, es más evidente la diferencia en la dispersión entre los dos periodos. Para los conjuntos con datos imputados, la diferencia en el rezago educativo entre los dos periodos es de $1.1 \%$, mientras que el porcentaje de personas sin derecho a servicios de salud en los conjuntos del primer periodo es de $30.4 \%$, y para el segundo periodo aumentó a 32.7 por ciento.

Adicionalmente, realizamos pruebas de análisis de la varianza para comparar el efecto del tiempo en las variables de educación y salud: ${ }^{9}$ porcentaje de niños que no asisten a la primaria, porcentaje de niños que no asisten a la secundaria, rezago educativo (porcentaje de personas mayores de 15 años sin educación básica completa) y porcentaje de población sin derecho a servicios de salud pública. En la segunda columna (Cuadro 3) se incluyen todos los conjuntos con datos imputados y en la tercera se reportan únicamente los resultados de los conjuntos en la cartografía digital.

9 Realizamos una suposición de "cohorte ficticia", es decir, tenemos los datos del último censo, pero comparamos los valores de los indicadores de las AGEB de los conjuntos residenciales más recientes con los de los conjuntos más antiguos. 


\section{Figura 4}

Mapa LISA del porcentaje de niños entre 6 y 12 años que no asisten a la primaria

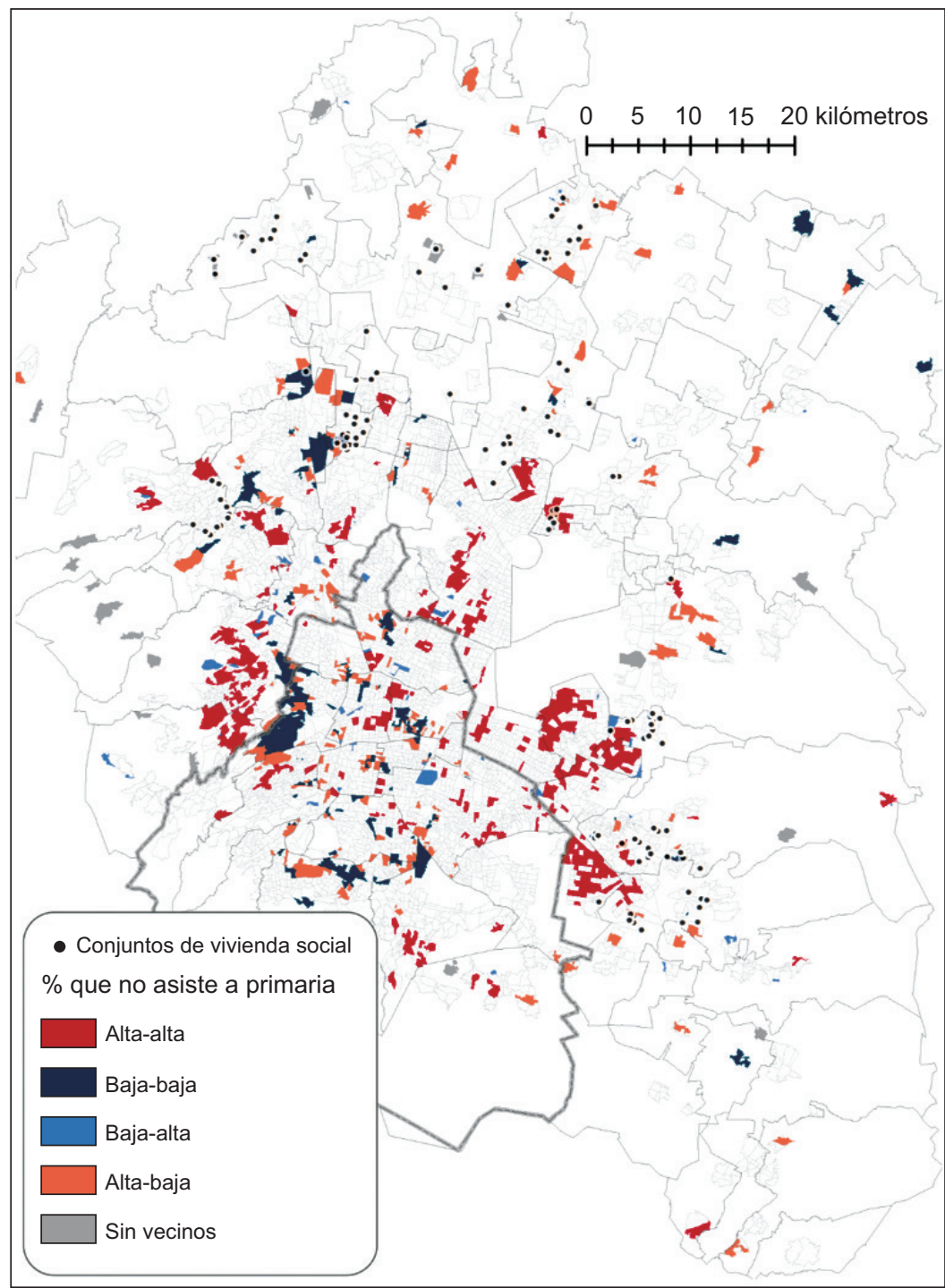

Fuente: Elaboración propia con base en INEGI, 2012b.

Estudios Demográficos y Urbanos, vol. 33, núm. 1 (97), 2018, pp. 187-224 ISSN 0186-7210; e-ISSN 2448-6515; doi: http://dx.doi.org/10.24201/edu.v33i1.1639 


\section{Figura 5}

Mapa LISA del porcentaje de niños entre 13 y 15 años que no asisten a la secundaria

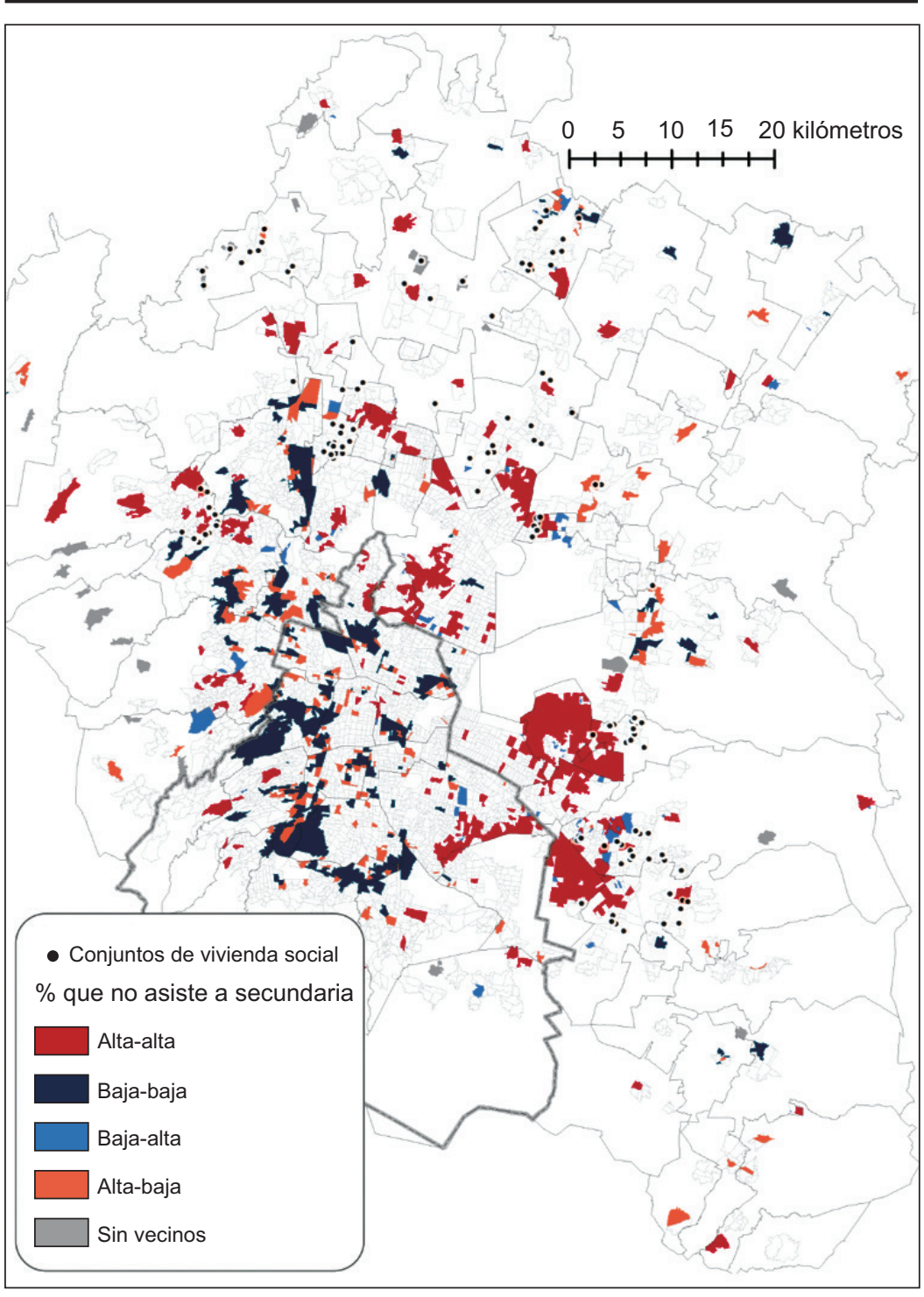

Fuente: Elaboración propia con base en INEGI, 2012b.

Estudios Demográficos y Urbanos, vol. 33, núm. 1 (97), 2018, pp. 187-224

ISSN 0186-7210; e-ISSN 2448-6515; doi: http://dx.doi.org/10.24201/edu.v33i1.1639 


\section{Figura 6}

Mapa LISA del porcentaje de mayores de 15 años sin educación básica finalizada

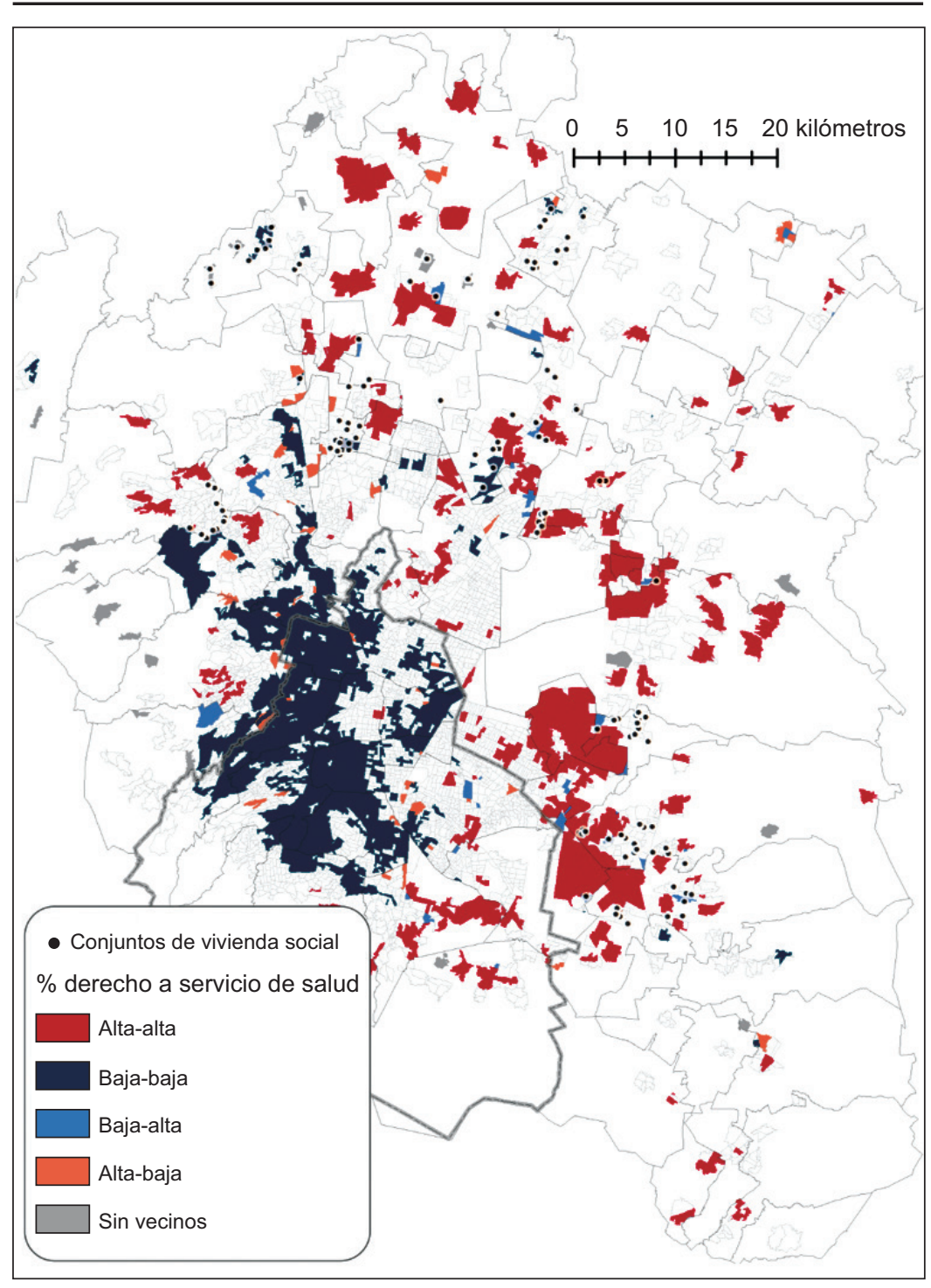

Fuente: Elaboración propia con base en INEGI, $2012 \mathrm{~b}$.

Estudios Demográficos y Urbanos, vol. 33, núm. 1 (97), 2018, pp. 187-224 ISSN 0186-7210; e-ISSN 2448-6515; doi: http://dx.doi.org/10.24201/edu.v33i1.1639 


\section{Figura 7}

Mapa LISA del porcentaje de viviendas con hacinamiento

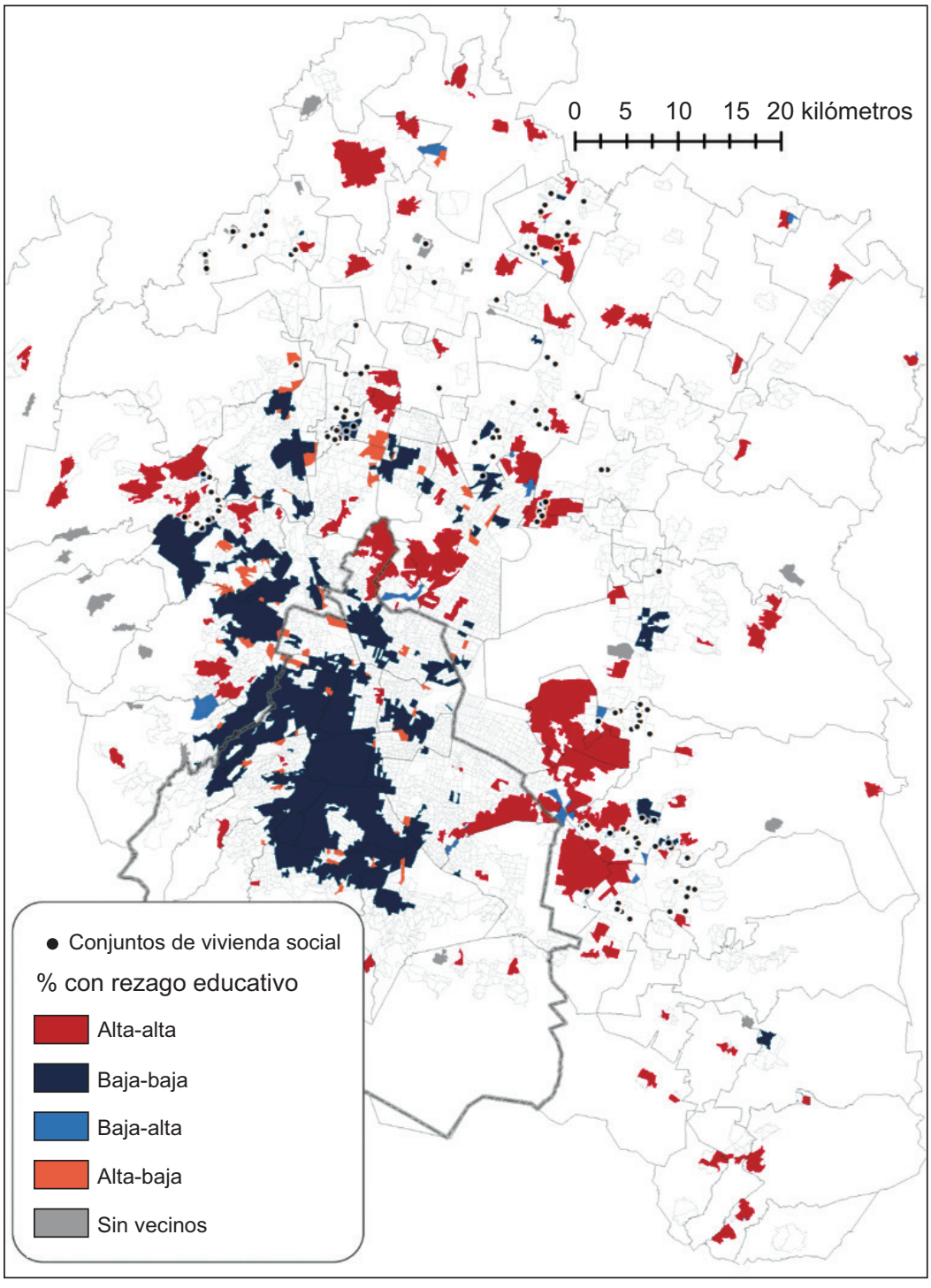

Fuente: Elaboración propia con base en INEGI, 2012b. 


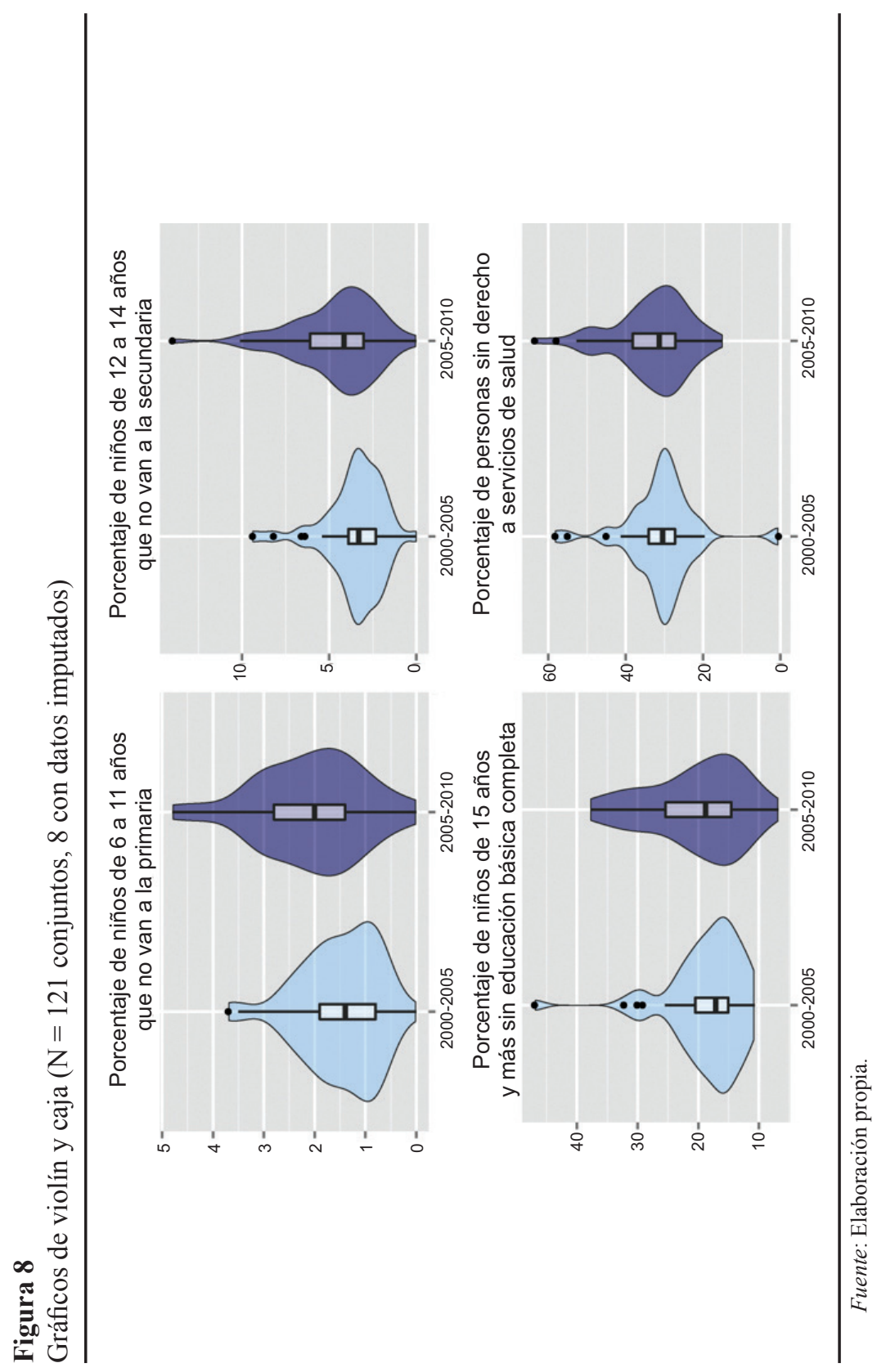




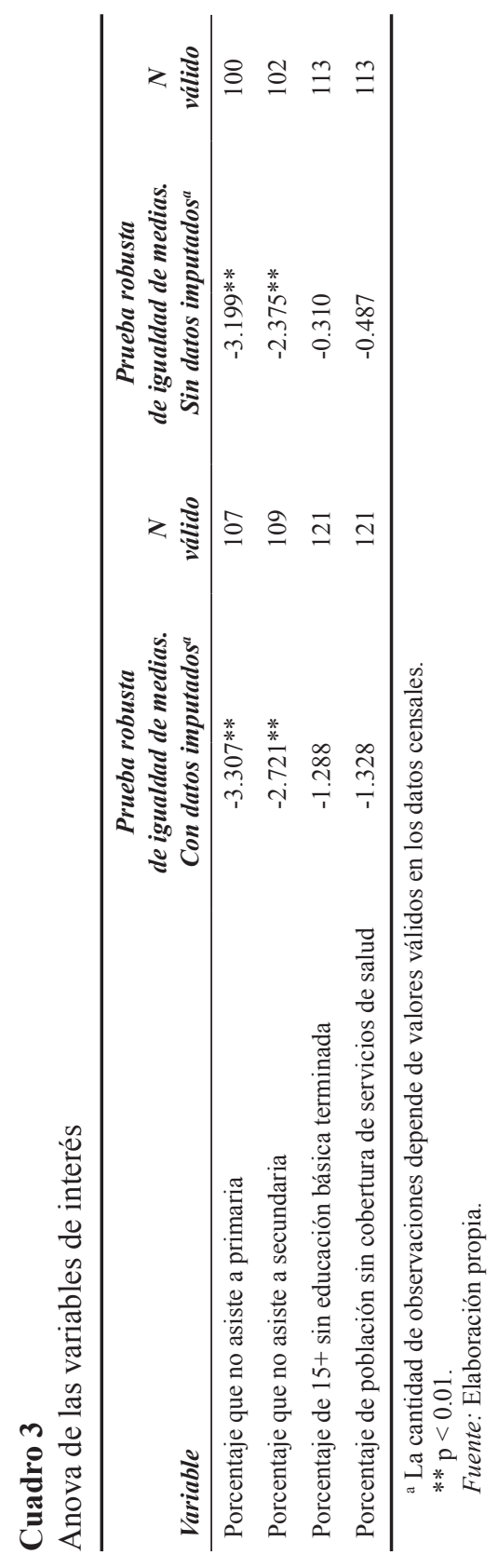


La diferencia entre el porcentaje de niños que no asisten a la escuela primaria y a la secundaria son los únicos indicadores que son distintos estadísticamente entre los dos periodos. Esto puede ser un indicio de que, con el paso del tiempo, mejora ligeramente la asistencia escolar; sin embargo, las diferencias en el rezago educativo y carencia de derecho a servicios de salud pública no son estadísticamente significativas. La interpretación de lo anterior podría ser que los patrones de segregación en el ciclo de vida de las familias se retroalimentan en el tiempo. Es decir, cuando llega el momento de incorporarse a la vida productiva, el abandono de la educación puede implicar que el único nicho laboral disponible esté vinculado a niveles bajos de educación formal: los sectores de comercio al por menor y la industria manufacturera.

\section{Índice de hacinamiento}

El análisis muestra un claro patrón de concentración de AGEB con altos porcentajes de hacinamiento (I de Moran de 0.64) en la periferia de la ZMVM. De los 121 conjuntos de vivienda social estudiados, la mayoría de ellos se encuentran en AGEB con autocorrelación positiva alta (Figura 9), es decir, con concentración espacial de valores altos de hacinamiento.

En el siguiente gráfico se muestra la distribución del porcentaje de viviendas con algún grado de hacinamiento de la ZMVM: en rojo se muestra el valor promedio metropolitano y en líneas punteadas los valores promedio municipales en las AGEB de los conjuntos analizados (Figura 10). La mitad de los municipios muestran valores por arriba del promedio metropolitano (25\%), siendo el peor caso Nextlalpan con casi $70 \%$ de sus viviendas con algún grado de hacinamiento. En el otro extremo se localiza Tepotzotlán, con apenas un valor promedio de 6.9 por ciento.

Al contrastar los valores de hacinamiento en los conjuntos habitacionales estudiados de acuerdo con su periodo de construcción (2001-2005 o 2005-2010), encontramos diferencias significativas entre los conjuntos más recientes, promediando $25 \%$ de viviendas con hacinamiento, en contraste con $16 \%$ en los más antiguos. Esto tiene implicaciones importantes en la calidad de vida. Parece que los pobladores efectivamente, con el paso del tiempo, tienden a expandir sus viviendas para lograr una mejor calidad de vida. ${ }^{10}$

${ }^{10}$ A este respecto habrá que resaltar la nueva política de vivienda promovida desde la Secretaría de Desarrollo Agrario, Urbano y Territorial (Sedatu), la Comisión Nacional de la Vivienda (Conavi) y el Instituto del Fondo Nacional de la Vivienda para los Trabajadores (Infonavit) desde el segundo semestre del 2015, cuyo objetivo es la reducción del hacinamiento mediante el otorgamiento de créditos individuales para ampliación. 


\section{Figura 9}

Mapa LISA de viviendas con hacinamiento en la ZMVM y los conjuntos de vivienda social 2001-2010

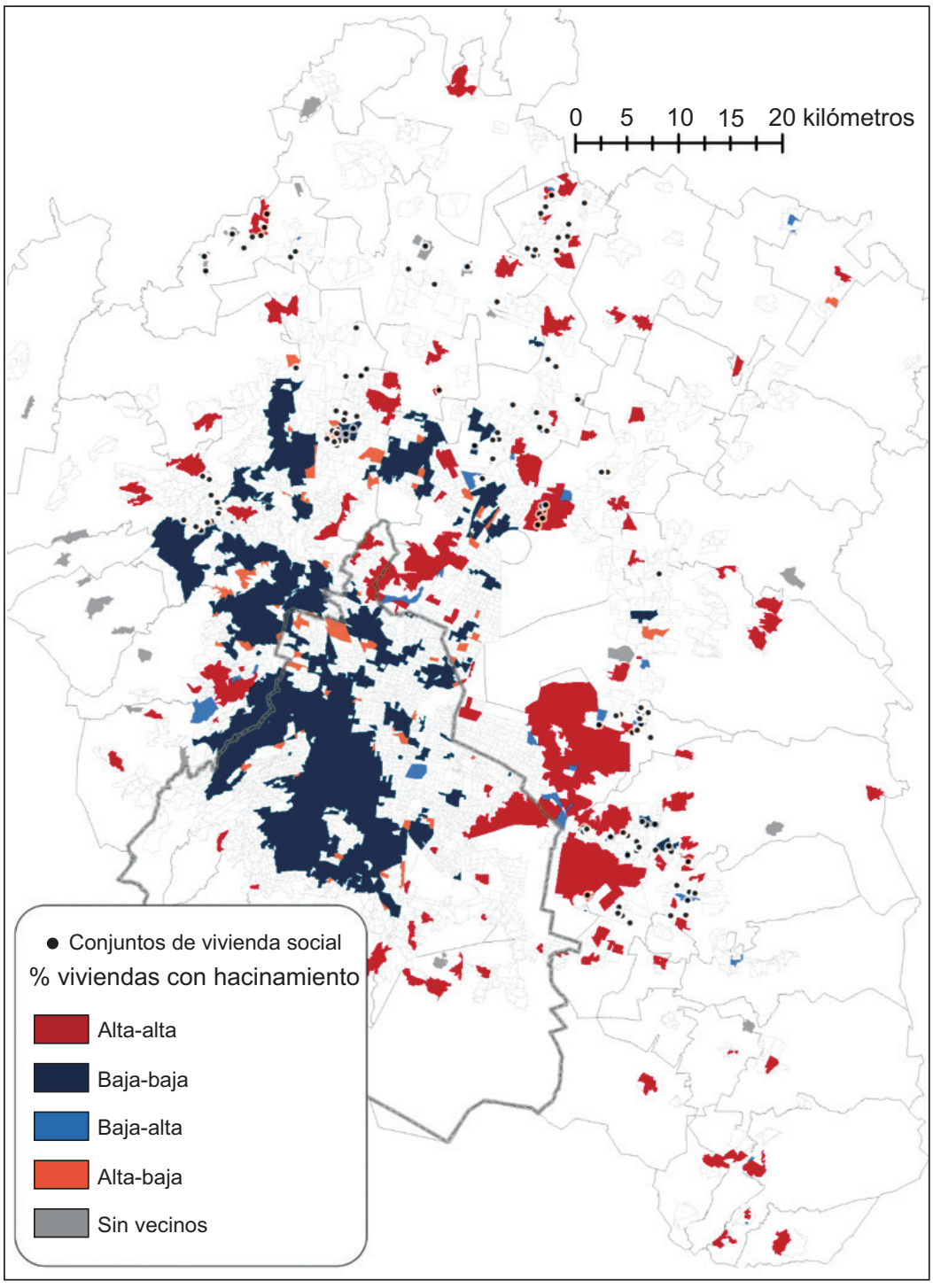

Fuente: Elaboración propia con base en INEGI, 2012b. 


\section{Figura 10}

Viviendas con hacinamiento en la ZMVM

y los conjuntos de vivienda social 2001-2010

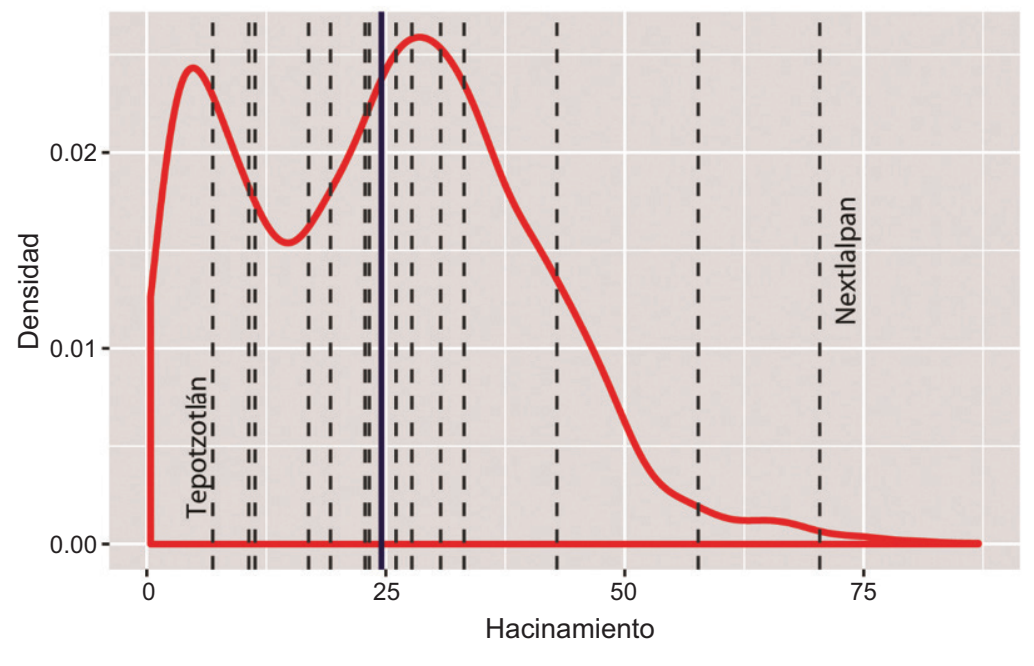

Fuente: Elaboración propia.

\section{Demanda y oferta de vivienda social}

De acuerdo con la Comisión Nacional de Fomento a la Vivienda (Conafovi, 2004), en 12 de los 14 municipios de estudio ${ }^{11}$ se necesitaba construir un total de 196593 nuevas viviendas en el periodo 2001-2010. No obstante, se construyeron 468583 viviendas, incorporando aproximadamente 7400 ha de suelo urbano. Ello significa que el número de viviendas ofertadas fue 2.4 veces mayor con respecto a la demanda federal proyectada.

De estos municipios, nueve presentan superávit y tres déficit de vivienda edificada (Figura 11 y Cuadro A1 del Anexo). Del grupo con superávit destacan Huehuetoca (con casi 12 veces más de lo proyectado oficialmente), Tecámac (7 veces más), Tizayuca (5.3), Cuautitlán (5.2) y Zumpango (4.6).

${ }^{11}$ Se excluyen de esta sección Valle de Chalco Solidaridad y Teoloyucan por falta de datos de planes. 


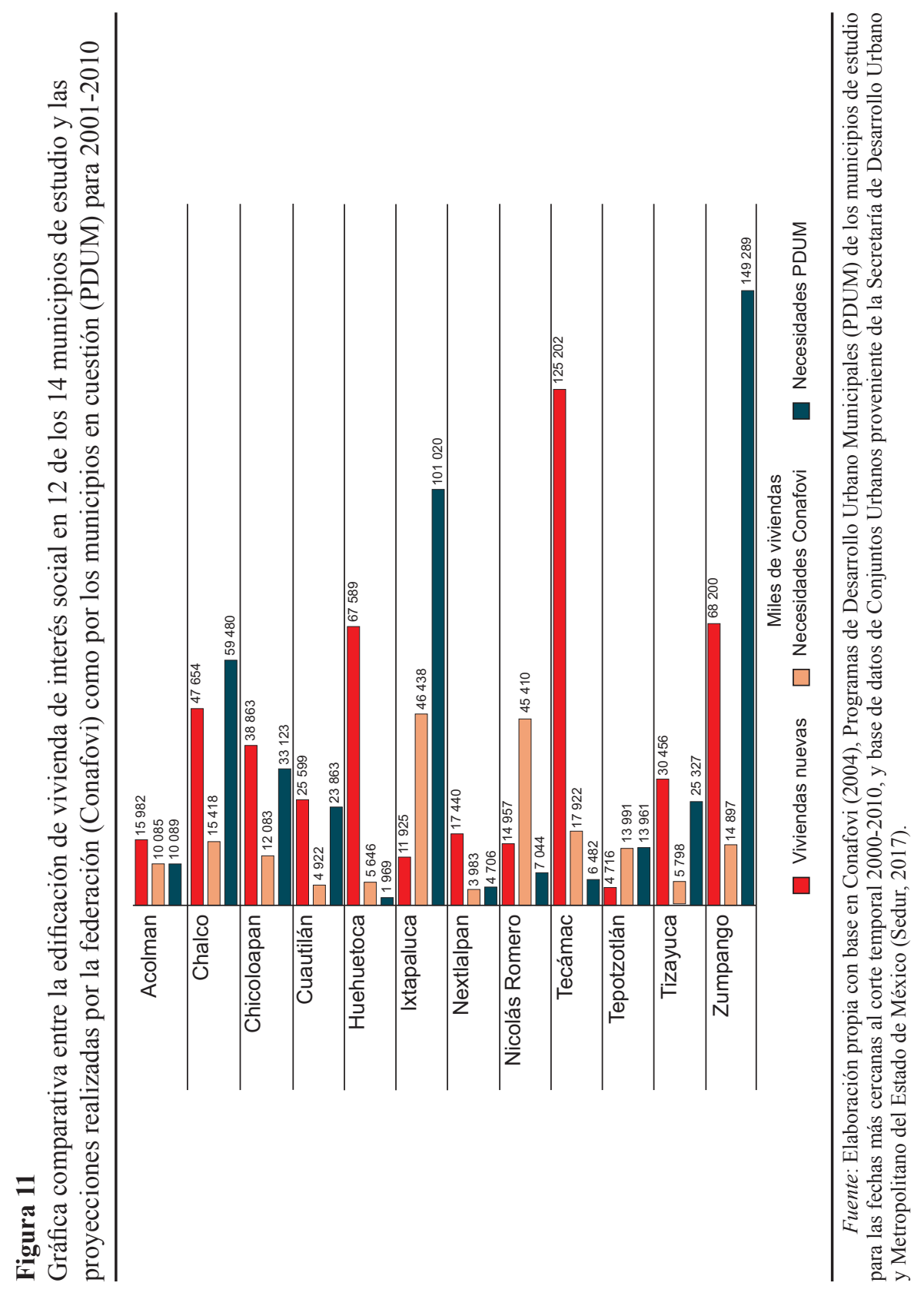


Al comparar la necesidad de vivienda nueva programada por los PDUM respecto a las proyecciones a nivel federal (Conafovi), también puede apreciarse una enorme desarticulación en los criterios políticos que norman el número de nuevas viviendas. Sin embargo, al comparar la vivienda nueva edificada con respecto a la proyectada por los PDUM, las diferencias se reducen. Para el total de municipios de estudio se edificó solamente $7 \%$ más de la demanda total. Ello sugiere dos situaciones: la primera es que las constructoras seguramente se guían más por las autoridades locales que por la demanda federal proyectada, y la segunda, que mientras en determinados municipios se exacerba la oferta, en otros queda incumplida la demanda mínima.

\section{Reflexiones finales}

En este trabajo se aprecia claramente un patrón de distribución espacial homogéneo en indicadores como hacinamiento, acceso a servicios de salud y rezago educativo en personas de quince años y más para gran parte de los municipios periféricos que albergan los nuevos conjuntos de vivienda social. En un nivel micro, esta segregación también se expresa en un limitado acceso a la primaria y la secundaria. En los conjuntos habitacionales analizados también se captaron bajos valores de accesibilidad al empleo en comercio al por mayor y a servicios. El comercio al por menor y la industria manufacturera son la oferta laboral más accesible para estos conjuntos, elemento que podría estar reforzando la segregación encontrada en cuanto al rezago educativo. Estos hallazgos reflejan lo planteado por Sabatini (2006) y por Sabatini, Cáceres y Cerda (2006), tanto en el sentido tradicional de la homogeneidad y concentración espacial de las condiciones de un grupo social en el espacio con respecto a otro, como en el sentido de la existencia de efectos negativos en la segregación residencial por la baja accesibilidad; también es consistente con lo señalado por Fuentes y Hernández (2013) sobre la base de una mayor segregación residencial por localización y acceso a los recursos urbanos. Como señalan Sabatini, Cáceres y Cerda (2001), existen diferentes escalas geográficas de marginación residencial. Su observación en Chile -extensible al modelo de ciudad latinoamericana- es que la escala geográfica de la segregación está cambiando a una mayor escala, y que su "malignidad" está aumentando. Para el caso de los municipios de estudio, se puede hablar de la presencia de ambos fenómenos y también de la existencia de segregación residencial en diferentes escalas geográficas, pues la concentración sostenida de grupos sociales homogéneos de bajos ingresos

Estudios Demográficos y Urbanos, vol. 33, núm. 1 (97), 2018, pp. 187-224 ISSN 0186-7210; e-ISSN 2448-6515; doi: http://dx.doi.org/10.24201/edu.v33i1.1639 
en la periferia permite que la escala de la segregación pase de una local a una regional, tal y como lo argumenta Monkkonen (2012; 2012a).

Sin embargo, parece ser que, con el paso del tiempo, la consolidación de los asentamientos reduce las condiciones de segregación en una escala geográfica de barrio. Ello ha sido recientemente corroborado por Caudillo y Flores (2016: 172), quienes analizando datos de 2000 y 2010 encuentran que el patrón de segregación a lo largo del tiempo de la ZMVM es "por expansión"; es decir, las zonas de alta segregación de 2000 han mejorado para 2010 y las zonas de alta segregación más recientes coinciden con las regiones de crecimiento de la ciudad. La ampliación de la vivienda, el autoempleo y la construcción de nuevos equipamientos urbanos son elementos que se asocian al proceso de maduración de los nuevos conjuntos de vivienda habitacional, lo cual explica la reducción del hacinamiento, el incremento en la asistencia escolar a nivel de primaria y secundaria, y el aumento en la autocontención laboral de algunos municipios. Ello reforzaría la tesis de Sabatini (2006: 10) sobre la visión dinámica de la segregación residencial: hay una transición de un estado de segregación residencial inicial (concentración de un grupo social y el espacio urbano compartido con otros grupos) a una segunda etapa de homogeneidad social en el espacio. Pero a diferencia de Sabatini, nosotros encontramos un dinamismo en un sentido tendente a la reducción de dicha homogeneidad espacial en una escala de barrio, pero compartiendo el principio de la homogeneidad en una escala regional en términos de accesibilidad a ciertos sectores de empleo y servicios básicos (educación y salud).

No obstante las afirmaciones anteriores, apreciamos en este estudio que la autocontención laboral empeoró en aquellos municipios que presentaron los porcentajes más altos de vivienda deshabitada (datos no presentados aquí), relación ya planteada por otros autores (Eibenschutz y Goya, 2010) y que constituiría un vector claro del fenómeno de segregación residencial por localización (Sabatini y Wormald, 2013). Si recordamos de nuevo a Monkkonen (2012), quien afirma que el aumento de la segregación residencial está relacionada en parte con las nuevas políticas de financiamiento de vivienda social en las periferias de las ciudades mexicanas debido a la homogeneización de habitantes de bajos ingresos en las periferias, como también en parte a las políticas de suelo, su impacto en el precio del mismo, y al papel del Estado como promotor indirecto de la segregación (Sabatini 2006), podríamos plantear que la descoordinación entre autoridades federales y locales en materia de vivienda social en México, expresadas en las inconsistencias entre vivienda proyectada y construida, han tenido un impacto en la segregación. Una cuestión central en el análisis de la segregación son los 
patrones observables en diferentes escalas y sus implicaciones en las condiciones de vida de la población. En un nivel metropolitano encontramos que los niveles de segregación y los patrones espaciales de localización de la población de los sectores populares son relativamente estables (predominantemente periféricos); sin embargo, en una escala más detallada (de barrio), hay una evolución lenta hacia una composición más diversa de la población. La mejoría en las condiciones de habitabilidad de los desarrollos inmobiliarios de vivienda social (emprendidos principalmente por sus habitantes) no modifica un elemento estructural de la metrópoli: la accesibilidad al empleo continúa siendo desfavorable para aquellos que viven en la periferia, exacerbando los efectos negativos de la segregación. 


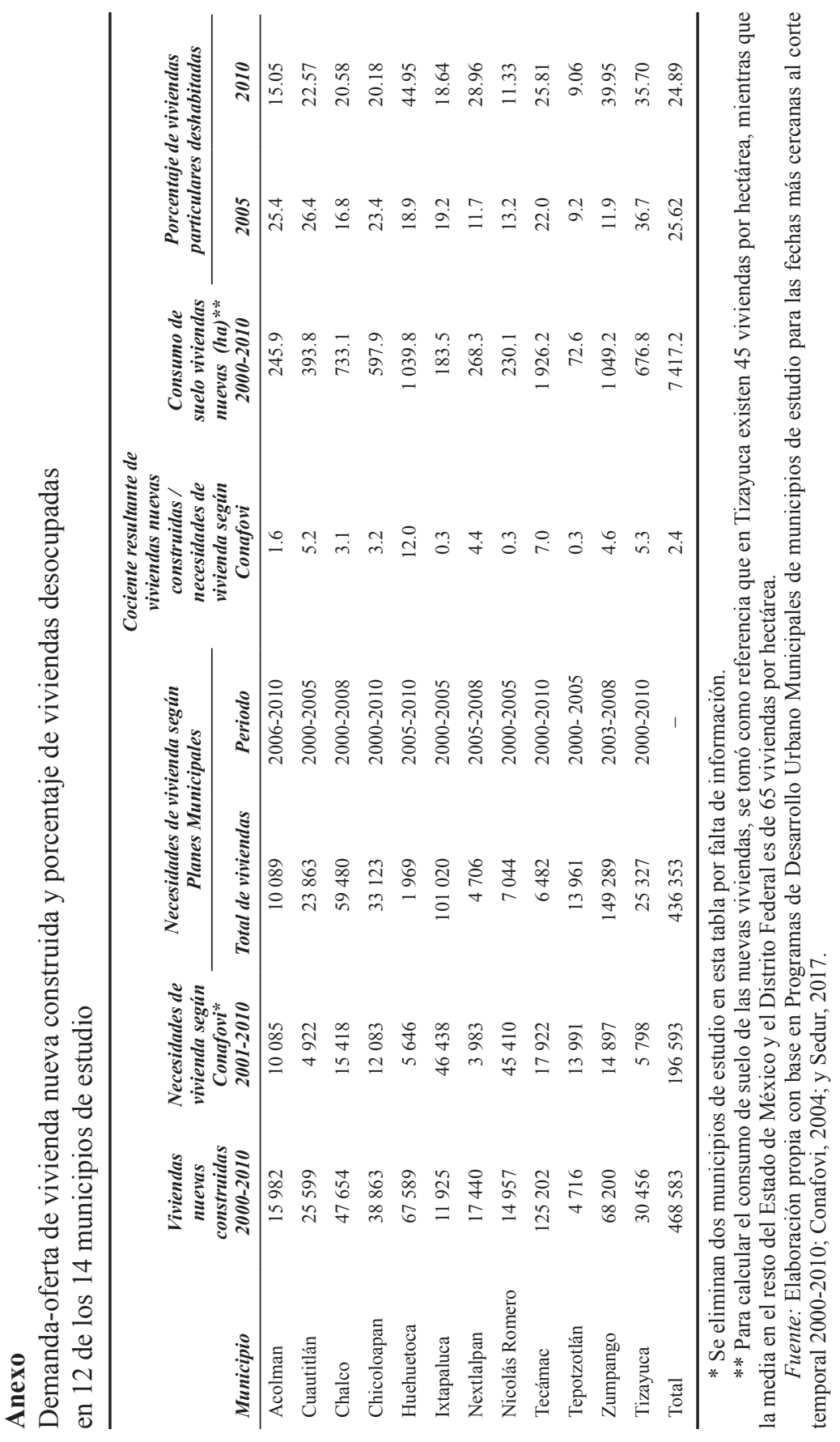




\section{Bibliografía}

Aldrete-Haas, José (1991), La deconstrucción del Estado mexicano: Políticas de vivienda, 1917-1988, México, Alianza.

Alegría, Tito (2009), Metrópolis transfronteriza: Revisión de la hipótesis y evidencias de Tijuana, México, y San Diego, Estados Unidos, México, El Colegio de la Frontera Norte / Miguel Ángel Porrúa.

Boils, Guillermo (2004), "El Banco Mundial y la política de vivienda en México", Revista Mexicana de Sociología, vol. 66, núm. 2, pp. 345-367. Recuperado de http://www.ejournal.unam.mx/rms/2004-2/RMS04204.pdf

Castells, Manuel (1976), La cuestión urbana, México, Siglo XXI

Catalán, Rafael (1993), Las nuevas políticas de vivienda, México, Fondo de Cultura Económica.

Caudillo, Camilo (2016), "De la casa al trabajo, evolución de la movilidad laboral", en Alejandro Mohar (coord.), Tendencias territoriales determinantes del futuro de la Ciudad de México, México, Consejo Económico y Social de la Ciudad de México / Consejo Nacional de Ciencia y Tecnología / CentroGeo, pp. 117-151.

Caudillo, Camilo y Socorro Flores (2016), "Tendencias espacio-temporales en la segregación”, en Alejandro Mohar (coord.), Tendencias territoriales determinantes del futuro de la Ciudad de México, México, Consejo Económico y Social de la Ciudad de México / Consejo Nacional de Ciencia y Tecnología / CentroGeo, pp. 153-175.

CIDOC (2004), "Estado actual de la vivienda en México 2004”, México, Centro de Investigación y Documentación de la Casa, A.C. / Sociedad Hipotecaria Federal.

CIDOC (2006), "Estado actual de la vivienda en México 2006”, México, Centro de Investigación y Documentación de la Casa, A.C. / Sociedad Hipotecaria Federal. CIDOC (2007), "Estado actual de la vivienda en México 2007”, México, Centro de Investigación y Documentación de la Casa, A.C. / Sociedad Hipotecaria Federal.

CIDOC (2011), "Estado actual de la vivienda en México 2011", México, Centro de Investigación y Documentación de la Casa, A.C. / Sociedad Hipotecaria Federal.

CIDOC (2012), "Estado actual de la vivienda en México 2012", México, Centro de Investigación y Documentación de la Casa, A.C. / Sociedad Hipotecaria Federal.

Conafovi (2004), Necesidades de vivienda 2001-2010, México, Comisión Nacional de Fomento a la Vivienda / Secretaría de Desarrollo Social.

Duncan, Otis y Beverly Duncan (1975), “A methodological analysis of segregation indexes", en Ceri Peach (ed.), Urban social segregation, Nueva York, Longman Group Limited, pp. 55-67.

Eibenschutz, Roberto y Carlos Goya (2010), "Estudio de la integración urbana y social en la expansión reciente de las ciudades en México, 1996-2006: Dimensión, características y soluciones", en Alfonso Iracheta y Enrique Soto (coords.), Impacto de la vivienda en el desarrollo urbano: Una mirada a la política habitacional en México, Zinacantepec, El Colegio Mexiquense, A.C., pp. 21-57.

Fuentes, César y Vladimir Hernández (2013), "Segregación socioespacial y accesi- 
bilidad al empleo en Ciudad Juárez, Chihuahua (2000-2004)”, Región y Sociedad, vol. 25, núm. 56, pp. 43-74. Recuperado de http://www.redalyc.org/articulo. oa? $\mathrm{id}=10225596012$

Galster, George y Sean Killen (1995), “The geography of metropolitan opportunity: A reconnaissance and conceptual framework", Housing Policy Debate, vol. 6, núm. 1, pp. 7-43. Recuperado de https:/www.innovations.harvard.edu/sites/ default/files/hpd_0601_galster2.pdf

Garcés-Fierros, César (2009), "Suelo urbano para la población pobre de México. La situación demográfica de México", en Consejo Nacional de Población (comp.), La situación demográfica de México, México, Conapo, pp. 87-102.

García, Beatriz (2010), "Vivienda social en México (1940-1999): Actores públicos, económicos y sociales”, Cuadernos de Vivienda y Urbanismo, vol. 3, núm. 5, pp. 34-49. Recuperado de http://revistas.javeriana.edu.co/index.php/cvyu/article/ view/5527

García, Beatriz y Claudia Puebla (1998), "El Infonavit en el contexto de las políticas habitacionales", en Martha Schteingart y Boris Graizbord (edits.), Vivienda y vida urbana en la Ciudad de México: La acción del Infonavit, México, El Colegio de México, A.C., pp. 21-85.

Garrocho, Carlos (2012), Estructura funcional de la red de ciudades de México, Zinacantepec, El Colegio Mexiquense, A.C. / Consejo Nacional de Población / Fondo de Población de las Naciones Unidas.

Garrocho, Carlos y Juan Campos-Alanís (2013), "Réquiem por los indicadores no espaciales de segregación residencial”, Papeles de Población, vol. 19, núm. 77, pp. 269-300. Recuperado de http://www.redalyc.org/pdf/112/11228794011.pdf Haas, Peter, Gajus Miknaitis, Harley Cooper, Linda Young y Albert Benedict (2010), Transit oriented development and the potential for VMT-related greenhouse gas emissions growth reduction, Berkeley, Center for Transit Oriented Development. Recuperado de http://ctod.org/pdfs/2010TODPotentialGHGEmissionsGrowth. pdf

INEGI (2010), Censo de Población y Vivienda 2010, México, Instituto Nacional de Estadística y Geografía.

INEGI (2012a), Directorio Estadístico Nacional de Unidades Económicas 2012, México, Instituto Nacional de Estadística y Geografía.

INEGI (2012b), Sistema para la consulta de información censal (Scinve, versión 05/2012), México, Instituto Nacional de Estadística y Geografía.

Kain, John F. (1968), "Housing segregation, negro employment, and metropolitan decentralization", The Quarterly Journal of Economics, vol. 82, núm. 2, pp.175197. Recuperado de https://www.jstor.org/stable/1885893?seq=1\#page_scan_ tab_contents

Lazcano Martínez, Mayra (2005), "El acceso al suelo y a la vivienda de los sectores informales: El caso de la Ciudad de México", Revista Invi, vol. 20, núm. 54, pp. 18-54. Recuperado de http://revistainvi.uchile.cl/index.php/INVI/article/ view/327/891 
Lindón, Alicia (1997), "De la expansión urbana y la periferia metropolitana", Documento de Investigación, 4, México, El Colegio Mexiquense, A.C. Recuperado de http://www.cmq.edu.mx/index.php/docman/publicaciones/doc-deinvestigacia-n/1

Massey, Douglas S. y Nancy A. Denton (1988), "The dimensions of residential segregation”, Social Forces, vol. 67, núm. 2, pp. 281-315. Recuperado de https:// www.jstor.org/stable/2579183?seq=1\#page_scan_tab_contents

Maya, Esther, Jorge Cervantes y Alfonso Rivas (2008), "Crítica a la promoción privada de grandes conjuntos urbanos habitacionales", ponencia presentada en el X Coloquio Internacional de Geocrítica "Diez años de cambios en el mundo, en la geografía y en las ciencias sociales, 1999-2008", Barcelona, Universitat de Barcelona, 26 a 30 de mayo.

Mellado, Roberto (2013), "La política de vivienda en las administraciones del Partido de Acción Nacional: 2000-2012, ponencia presentada en el Congreso Nacional de Vivienda 2013, PUEC-UNAM, México, 12 a 14 de marzo.

Metrópoli 2025 (2006), Una visión para la Zona Metropolitana del Valle de México, México, Centro de Estudios para la Zona Metropolitana.

Monkkonen, Paavo (2011), "Do Mexican cities sprawl? Housing-finance reform and changing patterns of urban growth", Urban Geography, vol. 32, núm. 3, pp. 406423. Recuperado de http://www.tandfonline.com/doi/pdf/10.2747/02723638.32.3.406? needAccess $=$ true

Monkkonen, Paavo (2012), "Housing finance reform and increasing socioeconomic segregation in Mexico", International Journal of Urban and Regional Research, vol. 36, núm. 44, pp. 757-772. Recuperado de http://onlinelibrary.wiley.com/ doi/10.1111/j.1468-2427.2011.01085.x/full

Monkkonen, Paavo (2012a), "La segregación residencial en el México urbano: Niveles y patrones", Eure, vol. 38, núm. 114, pp. 125-146. Recuperado de http:// www.scielo.cl/pdf/eure/v38n114/art05.pdf

Monkkonen, Paavo (2014), "The role of housing finance in Mexico's vacancy crisis", Documento de investigación, Los Ángeles, UCLA Luskin School of Public Affairs. Recuperado de: http://www.anderson.ucla.edu/Documents/areas/ctr/ ziman/2014-22WP.pdf (5 de enero de 2016).

Olivera, Guillermo (2005), "La reforma al artículo 27 constitucional y la incorporación de las tierras ejidales al mercado legal de suelo urbano en México", Scripta Nova. Revista Electrónica de Geografía y Ciencias Sociales, vol. 9, núm. 194 (33). Recuperado de: http://www.ub.edu/geocrit/sn/sn-194-33.htm

Perló, Manuel (1979), "Política y vivienda en México 1910-1952", Revista Mexicana de Sociología, vol. 41, núm. 3, pp. 769-835. Recuperado de https://www. jstor.org/stable/3540091?seq=1\#page_scan_tab_contents

Pradilla, Emilio (2000), La Ciudad de México hoy. Bases para un diagnóstico, México, Gobierno del Distrito Federal.

Rébora, Alberto (1978), "El ordenamiento territorial y urbano en México. Problemas 
y perspectivas”, Comercio Exterior, vol. 28, núm. 10, pp. 1181-1191. Recuperado de http://revistas.bancomext.gob.mx/rce/magazines/466/1/RCE2.pdf

Rébora, Alberto (2000), ¿Hacia un nuevo paradigma de la planeación de los asentamientos humanos? Políticas e instrumentos de suelo para un desarrollo urbano sostenible, incluyente y sustentable: el caso de la Región Oriente en el Valle de México, México, M.A. Porrúa.

Rodríguez, Gonzalo (2014), "Qué es y qué no es segregación residencial. Contribuciones para un debate pendiente", Biblio $3 W$. Revista Bibliográfica de Geografía y Ciencias Sociales, vol. 19, núm. 1079. Recuperado de http://www.ub.edu/ geocrit/b3w-1079.htm

Rodríguez, Jorge y Camilo Arriagada (2004), "Segregación residencial en la ciudad latinoamericana”, Eure, vol. 29, núm. 89, pp. 5-24. Recuperado de http://www. scielo.cl/pdf/eure/v30n89/art01.pdf

Rufino, Maria (2015), “O imobiliário como frente de expansão da metrópole: contradições na produção do espaço do Porto das Dunas”, Eure, vol. 41, núm. 124, pp. 69-90. Recuperado de http://www.scielo.cl/pdf/eure/v41n124/art04.pdf

Sabatini, Francisco (2006), "The social spatial segregation in the cities of Latin America", Documento de trabajo, Inter-American Development Bank. Recuperado de https://publications.iadb.org/handle/11319/716

Sabatini, Francisco, Gonzalo Cáceres y Jorge Cerda (2001), "Segregación residencial en las principales ciudades chilenas: Tendencias de las tres últimas décadas y posibles cursos de acción”, Eure, vol. 27, núm. 82, pp. 21-42. Recuperado de http://www.eure.cl/index.php/eure/article/view/1258

Sabatini, Francisco y Guillermo Wormald (2013), "Segregación de la vivienda social: reducción de oportunidades, pérdida de cohesión”, en Francisco Sabatini, Guillermo Wormald y Alejandra Rasse (coords.), Segregación de la vivienda social: ocho conjuntos en Santiago, Concepción y Talca, Santiago, Pontificia Universidad Católica de Chile, pp. 15-31.

Sedesol (2011), La expansión de las ciudades en México: 1980-2010, México, Secretaría de Desarrollo Social.

Sedesol (2012), Sistema Normativo de Equipamiento Urbano de México, tomo 1, Educación y cultura, México, Secretaría de Desarrollo Social. Recuperado de http://www.inapam.gob.mx/work/models/SEDESOL/Resource/1592/1/images/ educacion_y_cultura.pdf

Sedur (2017), Base de Datos de Conjuntos Urbanos, Toluca, Estado de México, Secretaría de Desarrollo Urbano y Metropolitano. Recuperado de http://portal2. edomex.gob.mx/sedur/informacion_de_interes/conjuntos_urbanos/2012/index. htm> (1 de enero de 2014).

Wormald, Guillermo, Carolina Flores y Alejandra Rasse (2013), "Segregación residencial, acceso a oportunidades sociales y vulnerabilidad a la pobreza en la Región Metropolitana de Santiago", en Francisco Sabatini, Guillermo Wormald y Alejandra Rasse (coords.), Segregación de la vivienda social: Ocho conjuntos en Santiago, Concepción y Talca, Santiago, Pontificia Universidad Católica de Chile, pp. 131-179. 


\section{Acerca de los autores}

Jorge Alberto Montejano Escamilla es arquitecto por la Universidad Iberoamericana (Ciudad de México) y doctor en Urbanismo por la Universitat Politécnica de Catalunya (Barcelona). Es profesor investigador en el Centro de Investigación en Geografía y Geomática "Ing. Jorge L. Tamayo" A. C. (CentroGeo) en la Ciudad de México, donde imparte cursos de estudios urbanos. Ha publicado artículos sobre la relación entre el comportamiento de viajes y el entorno construido, la estructura urbana, el crecimiento urbano, la vivienda social y el impacto de la tecnología en el entorno construido. Pertenece al Sistema Nacional de Investigadores (SNI) de México, nivel I, es miembro de la Academia Mexicana de Urbanistas (AMU) e integrante de la Red de Estudios sobre Forma Urbana (REFU). Su trabajo se ha publicado en revistas como Urban Studies, Urbs, Economía Sociedad y Territorio, entre otras.

Camilo Alberto Caudillo Cos es maestro en Estudios de Población por la Facultad Latinoamericana de Ciencias Sociales (Flacso-México), así como maestro en Geomática y candidato a doctor en Geomática por el Centro de Investigación en Geografía y Geomática "Ing. Jorge L. Tamayo" A.C. (CentroGeo). Actualmente es profesor investigador en el CentroGeo, donde imparte cursos de análisis espacial en el diplomado Análisis de Información Geoespacial y en la maestría de Planeación Espacial. Ha publicado recientemente artículos sobre segregación residencial, forma urbana, vivienda deshabitada en la Ciudad de México, relación entre el entorno construido y el comportamiento de viajes, por mencionar algunos. Sus trabajos han sido publicados en revistas como Urban Studies, Urbs, Ciudades, así como en editoriales como Springer. A lo largo de su trayectoria ha participado en diversos proyectos de vinculación que abordan fenómenos urbanos como: geografía del crimen y seguridad pública, migración de capital humano altamente capacitado, y movilidad laboral en la Ciudad de México.

Mauricio Cervantes Salas es licenciado en Biología por la Facultad de Ciencias de la UNAM, maestro en Demografía y doctor en Estudios de Población por El Colegio de México A.C. Actualmente es profesor investigador del Centro de Investigación en Geografía y Geomática "Ing. Jorge L. Tamayo", A.C. (CentroGeo), institución en la que ha impartido el seminario "Manejo comunitario de recursos naturales" para la maestría en Geomática, y el curso "Espacio y desigualdad" para la maestría en Planeación Espacial. Sus temas de interés en la investigación están relacionados con desigualdad, 
familia, territorio y manejo comunitario de recursos naturales. Sobre estos temas ha publicado: "Teoría de los campos de Bourdieu: una perspectiva para estudiar la conservación y el aprovechamiento forestal", en Joseph Weiss y Teodoro Bustamante (eds.), El ajedrez ambiental. Manejo de recursos naturales, comunidades, conflictos y cooperación. Quito, Flacso Ecuador / Ministerio de Cultura del Ecuador, 2008 (Serie 50 años); "Población y recursos naturales: el caso del agua" (en coautoría con Fernando Saavedra), en Conapo, La situación demográfica de México, 2003, México, Consejo Nacional de Población, 2004.

Fecha de recepción: 9 de junio de 2016.

Fecha de aceptación: 14 de agosto de 2017. 